\title{
Calculation of bedload transport in Swiss mountain rivers using the model sedFlow: proof of concept
}

\author{
F. U. M. Heimann ${ }^{1,2}$, D. Rickenmann ${ }^{1}$, M. Böckli ${ }^{1}$, A. Badoux ${ }^{1}$, J. M. Turowski ${ }^{3,1}$, and J. W. Kirchner ${ }^{2,1}$ \\ ${ }^{1}$ WSL Swiss Federal Institute for Forest, Snow and Landscape Research, 8903 Birmensdorf, Switzerland \\ ${ }^{2}$ Department of Environmental System Sciences, ETH Zurich, 8092 Zurich, Switzerland \\ ${ }^{3}$ Helmholtz Centre Potsdam, GFZ German Research Centre for Geosciences, Telegrafenberg, 14473 Potsdam, \\ Germany
}

Correspondence to: F. U. M. Heimann (florian.heimann@wsl.ch)

Received: 20 June 2014 - Published in Earth Surf. Dynam. Discuss.: 24 July 2014

Revised: 4 November 2014 - Accepted: 12 November 2014 - Published: 12 January 2015

\begin{abstract}
Fully validated numerical models specifically designed for simulating bedload transport dynamics in mountain streams are rare. In this study, the recently developed modelling tool sedFlow has been applied to simulate bedload transport in the Swiss mountain rivers Kleine Emme and Brenno. It is shown that sedFlow can be used to successfully reproduce observations from historic bedload transport events with plausible parameter set-ups, meaning that calibration parameters are only varied within ranges of uncertainty that have been predetermined either by previous research or by field observations in the simulated study reaches. In the Brenno river, the spatial distribution of total transport volumes has been reproduced with a Nash-Sutcliffe goodness of fit of 0.733; this relatively low value is partially due to anthropogenic extraction of sediment that was not considered. In the Kleine Emme river, the spatial distribution of total transport volumes has been reproduced with a goodness of fit of 0.949 . The simulation results shed light on the difficulties that arise with traditional flow-resistance estimation methods when macro-roughness is present. In addition, our results demonstrate that greatly simplified hydraulic routing schemes, such as kinematic wave or uniform discharge approaches, are probably sufficient for a good representation of bedload transport processes in reach-scale simulations of steep mountain streams. The influence of different parameters on simulation results is semi-quantitatively evaluated in a simple sensitivity study. This proof-of-concept study demonstrates the usefulness of sedFlow for a range of practical applications in alpine mountain streams.
\end{abstract}

\section{Introduction}

The rolling, sliding or saltating transport of sediment grains along river beds, which is summarised as bedload transport, represents one of the main morphodynamic processes in mountain streams. Bedload transport has implications which go beyond mere morphodynamics. It exerts considerable ecological influence by reorganising the bed and thus potential spawning grounds (e.g. Unfer et al., 2011). In mixed alluvial-bedrock channels, the bedload flux is one of the dominant controls on bedrock erosion (e.g. Turowski, 2012). Frequently, bedload fluxes are also responsible for damage to engineering structures (e.g. Jaeggi, 2008; Totschnig et al., 2011). Because bedload transport can amplify the impact of severe floods, it is also important in natural hazard management (e.g. Badoux et al., 2014). This wide range of implications is reflected in numerous applied engineering projects which evaluate potential bedload transport using one- or twodimensional simulation models. A summary of the applied aspects of bedload transport assessment has been given by Habersack et al. (2011).

The available models for simulating sediment transport may be divided into two groups. The first group of models does not focus on process details. It rather sees fluvial sediment transport as a part of a network of interacting processes within the landscape. Therefore, such models use simplified representations of river hydraulics and 
are often combined with hydrologic or soil erosion model components. Large-scale spatial resolutions and fast calculations are common in this group of models. The SHETRANsport model SHETRAN with SHE standing for Système Hydrologique Européen (Lukey et al., 2000; Bathurst et al., 2010), the Distributed Hydrology-Soil-Vegetation Model (DHSVM) (Doten et al., 2006) and others (e.g. Mouri et al., 2011) fall in this group. The SHE SEDiment component SHESED (Wicks and Bathurst, 1996) for the Système Hydrologique Européen also combines sediment transport routines with hydrologic and soil erosion routines, but without the strong simplifications (and associated efficiency gains) of the models mentioned above.

The second group of models concentrates on hydraulic processes as the main driving factor of sediment transport. Therefore, such models commonly solve the full SaintVenant equations, but neglect any processes outside the channel. Small-scale spatial resolutions and slow calculations are common in this group of models. The Steep Stream Sediment Transport 1-D model (3ST1D) (Papanicolaou et al., 2004), the Hydrologic Engineering Center model no. 6 (HEC-6) (Bhowmik et al., 2008), the model SEDROUT (Ferguson et al., 2001), the Generalized Stream Tube Alluvial River Simulation model (GSTARS) (Hall and Cratchley, 2006), the FLUvial Modelling ENgine (FLUMEN) (Beffa, 2005), the BASic EnvironMENT for simulation of environmental flow and natural hazard simulation (BASEMENT) (Faeh et al., 2011) and others (e.g. Lopez and Falcon, 1999; GarcíaMartinez et al., 2006; Li et al., 2008) fall in this group.

Similar to Tom ${ }^{\text {Sed }}$ (formerly known as SEdiment TRansport model in Alpine Catchments (SETRAC)) (Chiari et al., 2010), the model sedFlow (Heimann et al., 2015) is intended to bridge the gap between these two groups of models by providing good representation of fluvial bedload transport processes at intermediate spatial scales and high calculation speeds. Here the focus of modelling is not on the details of the temporal evolution of sediment transport, but rather on a realistic reproduction of the total transport volumes and overall morphodynamic changes resulting from sediment transport events such as major floods.

In spite of the considerable need for modelling tools in scientific and engineering applications and in spite of the interest in the relevant physical processes, bedload transport in mountain streams is not entirely understood. This is partly due to the complex measurement conditions in gravel-bed rivers (Bunte et al., 2008; Gray et al., 2010). Because of these difficulties, there are relatively few data sets available for deriving conceptual models or for validating and testing numeric models.

Based on the available field observations, it has become clear that river bed morphology and thus hydraulic processes become increasingly complex as channel gradients become steeper. The range of observed grain diameters becomes larger, which entails more complex grain-grain and grainflow interactions as well. Summarising available field data on flow velocity, Rickenmann and Recking (2011) showed that a considerable part of the river's shear stress is consumed by turbulence due to complex bed morphology, summarised as macro-roughness. They also suggested an approach to quantify the impact of macro-roughness based on the relative flow depth compared to a characteristic grain diameter. Lamb et al. (2008) and Bunte et al. (2013) have noted that in steep channels higher energies are needed for the initiation of bedload motion, compared to channels with gentle slopes. Turowski et al. (2011) have shown that the conditions for the initiation of bedload motion vary in time and are strongly linked to the conditions at the end of the last bedload transport event. Parker (2008) and Wilcock and Crowe (2003) have discussed and proposed approaches for quantifying grain-grain interactions in so-called hiding functions. Finally, several methods have been suggested for predicting bedload transport in mountain streams. Some of these methods are based on flume experiments, such as those of Rickenmann (2001) and Wilcock and Crowe (2003), and some are based on field observations, such as those of Recking (2010; 2013a). For recent applications and discussions of the conceptual models and methods mentioned in this paragraph see Chiari and Rickenmann (2011), Nitsche et al. (2011) and Rickenmann (2012). A selection of such methods related to the estimation of bedload transport in steep channels has been implemented in the modelling tool sedFlow. For the bedload transport equation, the flow-resistance relation and several other elements, sedFlow offers different options which can be selected to fit the current application in a particular catchment. The model architecture and implementation are described in detail in a companion article (Heimann et al., 2015), and are only briefly reviewed here. The program is intended for quantitatively simulating bedload transport processes in mountain streams at temporal scales from the individual event (several hours to few days) to longer-term evolution of stream channels (several years). It is designed for spatial scales covering complete catchments at a spatial discretisation of several tens of metres to a few hundred metres. sedFlow has been developed to provide a tool which combines recently proposed and tested process representations with fast computational algorithms and user-friendly file formats for easy pre- and postprocessing of simulation data.

In this article, we show that sedFlow can reproduce observations from historical bedload transport events, using plausible parameter set-ups. Here by plausible parameter set-ups we mean that calibration parameters are only varied within ranges of uncertainty that have been pre-determined either by previous research or by field observations in the simulated study reaches. The main aim of this proof-of-concept study is defined by the objective of the sedFlow model, namely the realistic simulation of total transport volumes and overall morphodynamic effects of sediment transport events such as major floods. The results of this study may help to interpret simulation results produced with sedFlow in applied engineering projects. Experiences with the simulation tool are dis- 


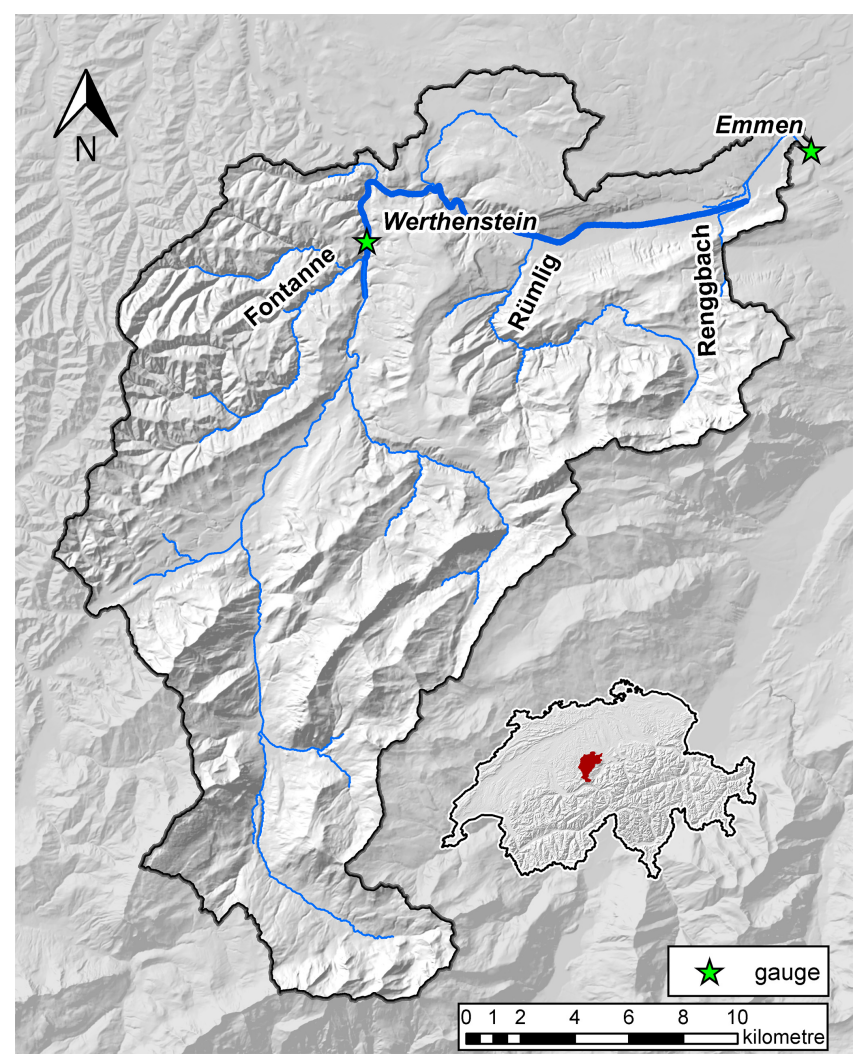

Figure 1. The Kleine Emme catchment in central Switzerland. The study reach from Doppleschwand to the confluence with the Renggbach is indicated by the bold blue line.

cussed with respect to the problems of quantifying the influence of macro-roughness within traditional flow-resistance equations. In addition, the uncertainties introduced by common graphical representations of bedload transport reconstructions are highlighted based on the results of a simple sensitivity study.

\section{Material and methods}

For our study we selected two Swiss rivers, the Kleine Emme and the Brenno (Figs. 1 and 2). The Kleine Emme was chosen because extensive data are available to validate and test the sedFlow model in this catchment. The Brenno river was selected as a complementary case study to cover a wider range of channel gradients and streambed morphology.

In this article we differentiate between net and gross channel gradients in the context of sills. Net channel gradients are defined as gross channel gradients corrected for the elevation differences attributable to sills or other drop-down structures.

\subsection{General catchment characteristics}

The Kleine Emme is a mountain river in central Switzerland (Fig. 1). It drains an area of $477 \mathrm{~km}^{2}$ and flows into the Reuss

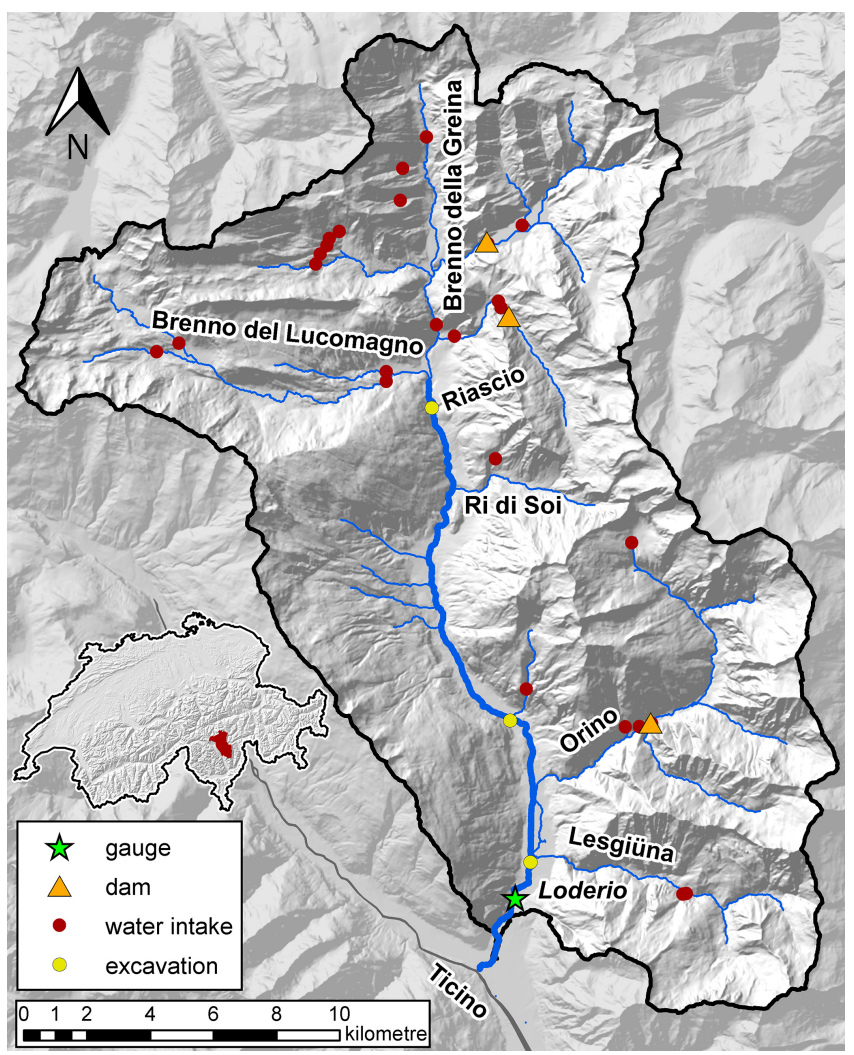

Figure 2. The Brenno catchment in southern Switzerland. The study reach from Olivone to Biasca is indicated by the bold blue line.

at Reussegg. The Kleine Emme's net channel gradient averages $0.8 \%$ with a maximum of $3.5 \%$. Near Doppleschwand the in situ bedrock is close to the surface, limiting the alluvium that can potentially be eroded. Further downstream the river was channelised in the late 19th and early 20th century. To mitigate the subsequent erosion, the bed was stabilised in the early 20th centuries with numerous bottom sills (documented by Geoportal Kanton Luzern, 2013). The Kleine Emme is an alpine mountain river catchment with gentle slopes, without glaciers or debris flow inputs and with only very moderate influence from hydropower installations, but with intensive modifications by fluvial engineering.

The Brenno is situated in southern Switzerland (Fig. 2) and drains into the river Ticino. Its drainage area is $397 \mathrm{~km}^{2}$ and its channel gradient averages $2.6 \%$, with a maximum of $17 \%$. There are no sills in the Brenno, so the net and gross gradients are the same. About $1 \%$ of the catchment area is glaciated. Especially in the northern and eastern part of the catchment, its hydrology is substantially influenced by hydropower (Fig. 2). The water used for hydropower production is returned to the Ticino river downstream of Biasca. The tributaries Riale Riascio and Ri di Soi are currently the most important sediment sources to the Brenno river (Table 1). The sediment input from the Riale Riascio is dominated by debris 
Table 1. Estimated sediment input yields from tributaries to the Brenno (based on Flussbau AG, 2003, 2005; Stricker, 2010) (Process types: $\mathrm{DF}=$ debris flow, $\mathrm{FT}=$ fluvial bedload transport).

\begin{tabular}{|c|c|c|c|c|c|c|c|}
\hline \multirow[t]{2}{*}{ Tributary } & \multirow[t]{2}{*}{ Type } & \multicolumn{3}{|c|}{ Per year $\left[\mathrm{m}^{3} \mathrm{a}^{-1}\right]$} & \multicolumn{3}{|c|}{ Calibration period $\left[\mathrm{m}^{3}\right]$} \\
\hline & & Min. & Mean & Max. & Min. & Mean & Max. \\
\hline Brenno della Greina & FT & 2500 & & 7500 & 25000 & & 75000 \\
\hline Brenno del Lucomagno/Ri di Piera & FT & 1500 & & 5000 & 15000 & & 50000 \\
\hline Riale Riascio & DF & 4000 & 10000 & 22000 & 40000 & 100000 & 220000 \\
\hline Ri di Soi & $\mathrm{DF}+\mathrm{FT}$ & 10000 & 20000 & 30000 & 100000 & 200000 & 300000 \\
\hline Lesgiüna & FT & 1000 & 2000 & 5000 & 10000 & 20000 & 50000 \\
\hline Crenone (Vallone) & DF & 1000 & 1500 & 4000 & 10000 & 15000 & 40000 \\
\hline
\end{tabular}

flows, while the larger subcatchment Ri di Soi delivers sediment both as debris flows and as fluvial bedload transport. Downstream of the confluences with these tributaries, the bed of the Brenno is stabilised by large blocks and the main channel shows pronounced knickpoints at these positions. Other tributaries on the western side of the Brenno catchment were very active in the decades from 1970 to 1990 , but their sediment delivery to the Brenno is much reduced at the time of writing due to intense torrent control works and sediment retention basins. The course of the Brenno is partially channelised and partially near natural. The Brenno represents a moderately steep mountain river influenced by glaciation, hydropower production and debris flow inputs.

The two catchments are impacted and show a range of engineering interventions typical of many mountain catchments. The Kleine Emme is marked by river training works, including numerous bottom sills as well as riprap and groynes in some locations. The Brenno is strongly influenced by controls on water and sediment delivery to the channel. The Brenno's hydrology is substantially influenced by hydropower production and lateral sediment input is limited by torrent control works and sediment retention basins in the tributaries. Along a few kilometres of the Brenno river gravel extraction occurred during the calibration period. The two catchments contrast with each other not only by their different management histories. Even though the two catchment areas are of similar size, channel gradients are steeper in the Brenno river than in the Kleine Emme river. While in the Kleine Emme channel bank erosion played a dominant role in feeding sediment to the transport system, in the Brenno lateral sediment input due to debris flows from tributaries was important during the calibration period. In summary, the two study catchments differ substantially and present a range of characteristics common to many mountain catchments.

Several channel cross sections are periodically surveyed for both rivers. In the case of the Kleine Emme, they are measured by the Swiss Federal Office for the Environment (FOEN) and in the case of the Brenno, they are measured by the authorities of the canton of Ticino. Cross-sectional profiles are recorded at $200 \mathrm{~m}$ intervals in the Kleine Emme and at about $150 \mathrm{~m}$ intervals in the Brenno. For the Kleine

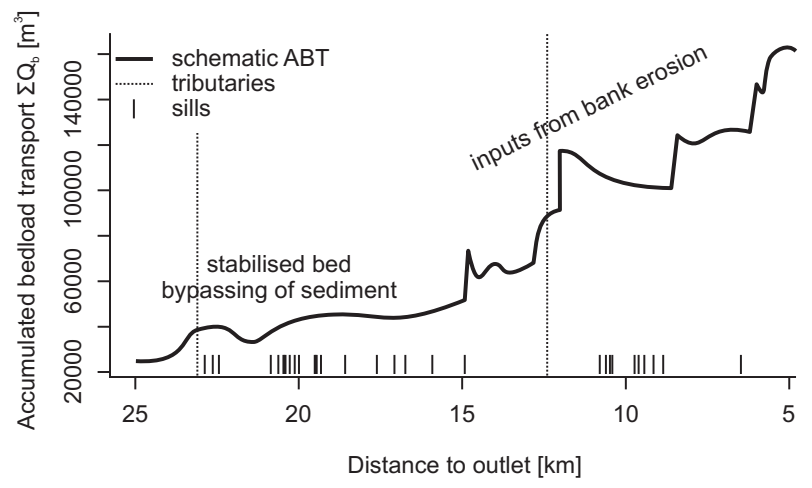

Figure 3. Schematic representation of accumulated bedload transport $(\mathrm{ABT})$ in the Kleine Emme with locations of tributaries and sills (tributaries from up- to downstream: Fontanne, Rümlig).

Emme we used measurements from September 2000 to November 2005. For the Brenno we used measurements from April 1999 to June/July 2009. We selected our study reaches to overlap with these surveyed cross sections.

Doppleschwand, about $25 \mathrm{~km}$ upstream from the Kleine Emme mouth, represents the upper boundary of our simulation reach. A large, long-duration flood event occurred in August 2005, with a return period of around 50 years for the peak discharge. During this event, widespread flooding occurred along the lowermost $5 \mathrm{~km}$ of the river in the area of Littau. Therefore, the lower boundary of our onedimensional model simulations is the confluence of the Kleine Emme and the Renggbach (Fig. 1). At the Brenno, our study reach extends from Olivone at the upper end to Biasca at the confluence with the Ticino river (Fig. 2).

\subsection{Hydrology}

The discharge of the Kleine Emme has been measured at Werthenstein since 1985 and at Littau-Emmen since 1978 (Fig. 1). Peak discharge at Littau-Emmen during the $\mathrm{Au}-$ gust 2005 flood was $650 \mathrm{~m}^{3} \mathrm{~s}^{-1}$. To account for the reduced catchment area of the Kleine Emme upstream of the Renggbach at the simulation outlet, the discharge at Littau-Emmen 
is reduced by $5 \%$ as suggested by VAW (1997). The discharge of the Rümlig tributary is estimated by the difference between the values of Werthenstein and the simulation outlet. The discharge of the Fontanne is simulated using the fully-distributed version of the Precipitation-RunoffEVApotranspiration HRU model PREVAH (Viviroli et al., 2009; Schattan et al., 2013) in which HRU stands for hydrological response units. The discharge of the headwater is estimated by the difference between the measured discharge at Werthenstein and the simulated Fontanne discharge.

Discharge of the Brenno has been measured at Loderio ever since the establishment of the hydropower reservoirs in the catchment in 1962. A peak discharge of $515 \mathrm{~m}^{3} \mathrm{~s}^{-1}$ was recorded during the July 1987 flood, corresponding to a return period of about 150 years. For the simulations, the discharge at Loderio has been distributed among the subcatchments according to rainfall-runoff simulations using the PREVAH model. The discharge is assumed to be zero at dams and reduced by the intake capacity at water intakes. In this reduction, we accounted for the regulations that specify the minimum residual discharge in the river channel downstream of a water intake. The values of this minimum residual discharge were defined based on ecological aspects and vary with intake location and time of the year.

\subsection{Channel morphology and bedload observations}

\subsubsection{Rectangular channels}

For use in the sedFlow model, the cross-sectional profiles were transformed into the equivalent width of a simple rectangular substitute channel. For this transformation a representative discharge was defined as the mean of the peak discharge of the simulation period and the discharge at the initiation of bedload motion, as these two values define the range of discharges relevant for bedload transport. The variable power equation flow-resistance relation was used to translate discharge into flow depth based on the same grainsize distributions (GSDs) that were used in the simulations. Then, a rectangular channel was found which has the same cross-sectional flow area and hydraulic radius as the original cross-sectional profile at this flow depth. The channel of the Kleine Emme has been regulated in the past and its geometry is well defined by a trapezoidal profile with steep banks. In contrast, the Brenno study reach is in a natural condition over most parts, including both more incised reaches with a well-defined width and depositional reaches in flatter areas with riparian forest. The latter reaches are characterised by river banks with gentle slopes. In such channels, a slight change of the representative discharge may result in a substantial change in the width of the rectangular substitute channel. Therefore, in the depositional reaches of the Brenno, the uncertainty in representative discharge entails a considerable uncertainty in substitute channel widths, which contrasts with the better-constrained substitute chan- nel widths in the incised Brenno reaches and Kleine Emme reaches, due to their steeper banks.

\subsubsection{Reference data}

To test the sedFlow model, a reference is needed, to which the simulation results can be compared. Therefore, the bedload transport during the calibration period, which was not observed by itself, needs to be reconstructed from available observations. To volumetrically quantify the reconstructed bedload transport, the change in average bed level between each pair of cross-sectional surveys is multiplied with the mean of the substitute channel width of both profile measurements and with the distance to the next profile. These bed volume changes give an integrated value of the minimum bed material transported over the observation period. However, to obtain a complete sediment budget, data on bank erosion, lateral sediment input from tributaries and the material that leaves the catchment at the outflow have to be considered. At the Kleine Emme, bank erosion volumes were estimated from the difference between the FOEN cross-sectional profiles in 2000 and 2005 and from field assessments of the erosion scars (Flussbau AG, 2009; Hunzinger and Krähenbühl, 2008), and the sediment outflow was quantified based on data of regular gravel extraction at the confluence of the Kleine Emme with the Reuss (Hunzinger and Krähenbühl, 2008; Hunziker, Zarn and Partner AG, 2009). For the Brenno the lateral inputs by debris flows or fluvial bedload transport were estimated based on data from a number of previous studies (Flussbau AG, 2003, 2005; Stricker, 2010), as listed in Table 1. The spatial pattern of changes in sediment transport, as well as the absolute value of sediment transport, is greatly influenced by sediment input from the tributaries. Thus, the uncertainty in the estimates of tributary sediment inputs largely determines the overall uncertainty in sediment transport in the Brenno. The sediment outflow at the mouth of the Brenno and thus the volume of the throughput load of the complete system is unknown. Therefore, we used the result of the sedFlow simulations as a best guess for this parameter, since no other proxies are available. Of course, this approach for the determination of sediment outflow at the mouth of the Brenno partially compromises the independence of the evaluation of model performance, regarding the overall transport rate. However, this approach still allows for an independent evaluation of the along-channel changes in transport rates as well as any other variables such as erosion and deposition rates or characteristic bed surface grain diameters.

\subsubsection{Accumulated bedload transport}

All volumetric data related to the sediment budget are summarised in accumulated bedload transport (ABT) diagrams, e.g. Figs. 3 and 4. ABT represents the net bedload amount which has been transported through a given stream section during the period of interest (Chiari et al., 2010). It is a tem- 


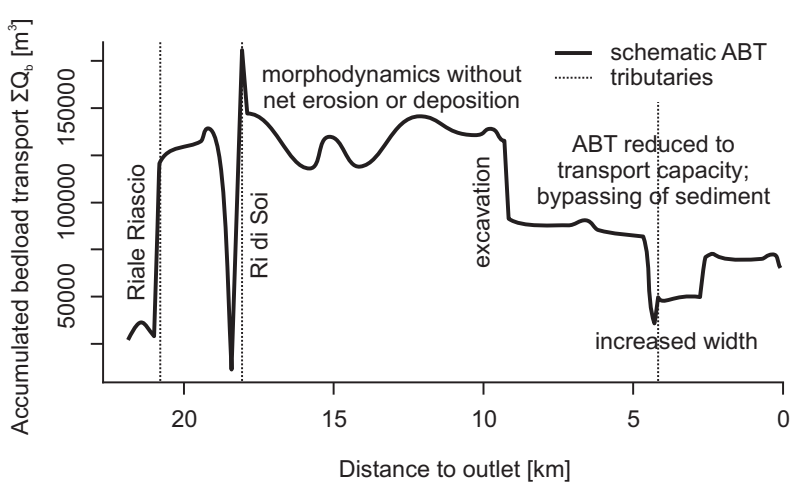

Figure 4. Schematic representation of accumulated bedload transport $(\mathrm{ABT})$ in the Brenno, with labels indicating major sediment sources and sinks (tributaries from up- to downstream: Riale Riascio, Ri di Soi, Lesgiüna).

poral integral of the transport rates and it is a spatial integral of the volumetric changes including bed net erosion and deposition, lateral inputs and sediment outflow. In this article, all ABT values include an assumed pore volume fraction of $30 \%$. The ABT can be derived from the morphodynamic relation, which has been described by Exner in its continuous form (e.g. Parker, 2008):

$$
\left(1-\eta_{\text {pore }}\right) \cdot \frac{\partial z}{\partial t}=q_{\mathrm{b}_{\mathrm{lat}}}-\frac{\partial q_{\mathrm{b}}}{\partial x} .
$$

Here $\eta_{\text {pore }}$ is the pore volume fraction, $z$ is elevation of channel bed, $t$ is time, $q_{\mathrm{b}}$ is sediment flux per unit flow width, $x$ is distance in flow direction and $q_{\mathrm{b}_{\text {lat }}}$ is lateral sediment influx per unit flow width. Equation (1) represents a balance of input and output volumes and it can be rewritten in a discretised form for a finite reach and period of time as

$V_{\text {in }}-V_{\text {out }}-V_{\text {EroDepo }}=0$,

$V_{\text {in }}=V_{\text {inUp }}+V_{\text {inLat }}$,

$V_{\text {out }}=V_{\text {cap }}$.

Here $V_{\text {in }}$ designates the volume of sediment that enters a reach, subdivided into the volume $V_{\text {inUp }}$ coming from upstream and the volume $V_{\text {inLat }}$ introduced laterally, e.g. by tributaries or bank erosion. $V_{\text {EroDepo }}$ is the volume eroded or deposited in the reach, with positive values indicating deposition. $V_{\text {out }}$ is the volume that exits the reach, which in the case of unlimited (or at least sufficient) supply of material (Eq. 4) equals the volume $V_{\text {cap }}$ corresponding to the transport capacity within the reach, multiplied by the considered time interval. Equation (2) constitutes the difference between inputs and outputs is counterbalanced by erosion or deposition (Fig. 5). For erosion, the local $V_{\text {in }}$ will always be smaller than $V_{\text {cap }}$ and will result in ABT increasing downstream. In the same way, deposition will result in a decreasing $\mathrm{ABT}$, while a roughly constant ABT reflects throughflow of sediment without net erosion or deposition.

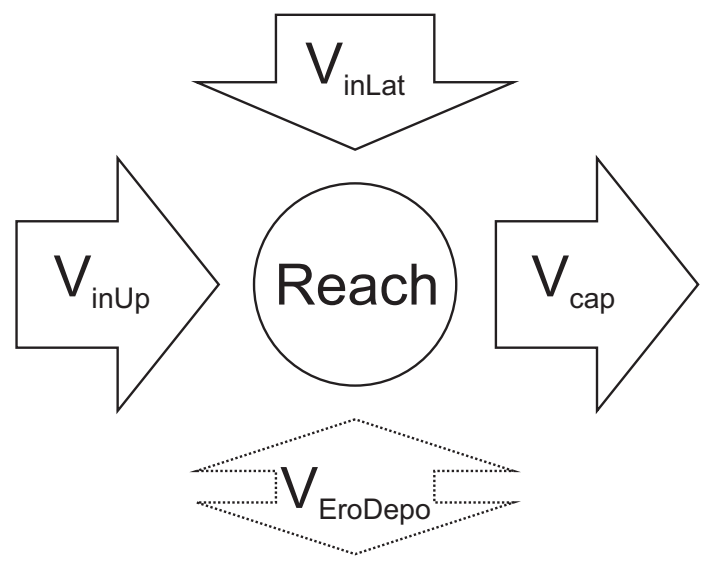

Figure 5. Schematic visualisation of Eqs. (2) to (4).

GSDs have been estimated for different reaches, based on transect pebble counts using the method of Fehr (1986, 1987). To determine the subsurface GSD, the pebble count was transformed into a full GSD by assuming an average proportion of $25 \%$ fine material with $D<10 \mathrm{~mm}$ according to Fehr (1987). To determine the surface GSD, the pebble count was transformed into a full GSD by assuming an average proportion of $10 \%$ fine material with $D<10 \mathrm{~mm}$ according to observations reported in Recking (2013b) and Anastasi (1984). In some cases at the Brenno, coarser sediment portions were added to the recorded GSDs, because coarse blocks have been underrepresented in the transect counts and thus the original transect GSDs partially led to unrealistic model behaviour. The measured GSDs were assumed to be representative for entire reaches, which are separated from each other by features such as confluences or considerable changes in channel gradient. This spatial extrapolation entails some uncertainty. The current GSD measurements, which were obtained after the end of the calibration period, are used as proxy estimates for the initial GSDs at the beginning of the calibration period. This time shift introduces additional uncertainty.

The bedload transport system of the Kleine Emme can be subdivided into two regimes (Fig. 3). In the upper part from 25 to $\sim 15 \mathrm{~km}$, the bed is stabilised by in situ bedrock and numerous sills. Therefore, the system is dominated by throughflow of sediment without considerable trends or jumps in the along-channel evolution of the ABT. In the lower part from $\sim 15$ to $5 \mathrm{~km}$, the bedload transport system is mainly influenced by sediment inputs from bank erosion during the 2005 flood event, which increase the downstream ABT in a steplike way.

The Brenno bedload transport system is mainly influenced by local elements (Fig. 4). The Riale Riascio at $20.8 \mathrm{~km}$ introduced a considerable amount of sediment to the system, resulting in a step-like downstream increase in the ABT. Large amounts of the material delivered by the Ri di Soi at $18.1 \mathrm{~km}$ have been deposited at the confluence. These de- 
posits reduced upstream channel gradients and thus transport capacity. The lack of material coming from upstream is overcompensated by the input from the Ri di Soi. However, the excess material has been deposited shortly after the confluence. All processes around the confluence with the Ri di Soi are reflected in a pronounced negative peak and small positive peak in the along-channel evolution of the ABT. The following stretch down to $10 \mathrm{~km}$ exhibits erosion and deposition corresponding to the interaction of GSD, channel gradient and width, but without any overall erosion or deposition trend. At $10 \mathrm{~km}$ sediment has been anthropogenically extracted from the riverbed by excavation, which results in a step-like downstream decrease of ABT. Because the excavation reduces the amount of transported material down to the transport capacity of the river, sediment bypasses the following reaches. At $4.5 \mathrm{~km}$, the deposits at the confluence with the Lesgiüna decrease the upstream slope and thus cause a drop in transport capacity. In the stretch from 4.5 to $3 \mathrm{~km}$, an increased channel width keeps the ABT at low values.

\subsection{The model sedFlow}

The bedload transport modelling tool sedFlow has been designed especially for application to mountain rivers. Consistent with this objective, it exhibits the following main features: (i) it uses recently proposed and tested approaches for calculating bedload transport in steep channels accounting for macro-roughness, (ii) it calculates several grain diameter fractions individually, i.e. fractional transport, (iii) it uses fast algorithms and thus can be used for modelling complete catchments and for scenario studies with automated calculations over many variations in the input data or parameter set-up. Here we give a short overview of the essential components of sedFlow. For a detailed account of the model structure and implementation see Heimann et al. (2015). The current version of the sedFlow code and model can be downloaded at the following web page: www.wsl.ch/sedFlow.

Flow resistance is either calculated with the variable power equation of Ferguson (2007) according to Eq. (5) or with a grain-size-dependent Manning-Strickler equation (Eq. 6):

$$
\begin{aligned}
& \frac{v_{m}}{v^{*}}=\frac{a_{1} a_{2}\left(\frac{r_{\mathrm{h}}}{D_{84}}\right)}{\sqrt{a_{1}^{2}+a_{2}^{2}\left(\frac{r_{\mathrm{h}}}{D_{84}}\right)^{\frac{5}{3}}}}, \\
& \frac{v_{m}}{v^{*}}=a_{1}\left(\frac{r_{\mathrm{h}}}{D_{84}}\right)^{\frac{1}{6}} .
\end{aligned}
$$

Here $v_{m}$ is the average flow velocity, $v^{*}=\sqrt{g r_{\mathrm{h}} S}$ is the shear velocity, $r_{\mathrm{h}}$ is the hydraulic radius, $S$ is the gradient of hydraulic head, which may be approximated by the gradient of the water surface or channel bed, $D_{84}$ is the characteristic grain diameter of the surface material, for which $84 \%$ of the material is finer, and $g$ is gravitational acceleration. Equation (5) has been tested by Rickenmann and Recking (2011) based on nearly 3000 field data points. With the coefficients $a_{1}=6.5$ and $a_{2}=2.5$, it shows very good agreement with the average trend of observations, especially including small relative flow depths that are characterised by high flow resistance. Rickenmann and Recking (2011) also rewrote Eq. (5) in an alternative version, in which flow velocity is written as a direct function of $q$, the discharge per unit flow width.

sedFlow allows three methods for the calculation of channel hydraulics: an explicit kinematic wave routing, an implicit kinematic wave routing and a uniform discharge approach.

The explicit flow routing corresponds to a Eulerian forward approach. In such an approach, all relevant variables are assumed constant for the duration of one time step. For numeric stability, time steps have to be short enough for this approximation to be valid. For morphodynamic simulations this may be impractical. The fast process of running water defines the short time step lengths, even though it is not the process of interest and the relatively slower morphodynamic changes would allow for much longer time steps and thus faster calculations. Apart from this disadvantage, the explicit flow routing provides a routing of discharge without any restrictions concerning other concepts or parameters.

To overcome the short time steps, sedFlow also provides capabilities for implicit flow routing. Because they are unconditionally stable, implicit methods impose no requirements concerning the length of time steps. However, in implicit methods the unknown variables usually have to be found via computationally demanding iterations. In sedFlow, the algorithm of Liu and Todini (2002) is implemented for solving the implicit flow routing. It avoids time-consuming iterations by analytically finding the solution using Taylor series approximations. However, this algorithm requires a power-law representation of discharge as a function of water volume in a reach. That means it can only be applied to infinitely deep rectangular or $\mathrm{V}$-shaped channels in combination with a power-law flow resistance such as Eq. (6). Except for this restriction, the implicit flow-routing algorithm provides a routing of discharge with fast computational performance.

The explicit and implicit flow routings use the bed slope as proxy for energy slope for all hydraulic and bedload transport computations. This approximation, which corresponds to the assumption of a kinematic wave, is acceptable for most mountain channels, as river bed gradients are commonly steep there. However, problems arise when tributaries deposit debris flow material in the main channel, producing adverse slopes (uphill slopes in the downstream direction). A pragmatic solution to deal with adverse slopes is the uniform discharge approach. Discharge is assumed to be equal along the entire channel, only increasing at confluences for a given time step. This procedure can be justified keeping in mind that the temporal scale of hydraulic processes is very small compared to the temporal scale of morphodynamic processes. Hydraulic calculations are performed using 
the bed slope proxy for the hydraulic gradient. In cases of adverse slopes, ponding is simulated. That is, flow depth and velocity are selected to ensure a minimum gradient of hydraulic head, which is positive and close to zero. For bedload transport calculations the gradient of the hydraulic head is used, which by definition can only exhibit positive slopes. Thus, the energy slope for bedload transport estimation is not the result of a backwater calculation, but it is the gradient between individual hydraulic head values, which under normal conditions have been calculated independently from each other using the local bed slope as a proxy for friction slope. It has to be noted that this approach will produce large errors if moderate backwater effects are part of the simulated system. In such systems, the other approach, which uses bed slope both as the friction slope for the hydraulic calculations and as the energy slope for the sediment transport calculations, will produce better estimates of the transported sediment volumes, but it cannot accommodate adverse channel gradients.

Partially due to the simple and efficient hydraulic schemes, several years of bedload transport and resulting slope and GSD adjustment can be simulated with sedFlow within only few hours of calculation time on a regular $2.8 \mathrm{GHz}$ central processing unit (CPU) core.

For optimising calculation speed, amongst others the time steps should be as long as possible. However, there are stability concerns that limit the potential time step lengths. Within sedFlow, the time step length used for the current time step is obtained from three different methods of calculation. When explicit or implicit kinematic-wave flow routing is used, the first method ensures that local slope changes do not exceed a user-defined fraction. When explicit kinematicwave flow routing is used, the first method further calculates another time step length based on the Courant-FriedrichsLewy (CFL) criterion (Courant et al., 1928) for the water flow velocity multiplied by a user-defined safety factor ${ }^{1}$. The second method is based on the CFL criterion for the estimated bedload grain velocity multiplied by a user-defined safety factor. The third method ensures that erosion of the active layer is always less than a user-defined maximum fraction. The actual time step length is the minimum of the values obtained for each simulated reach from the three methods described in this paragraph, provided that this minimum is smaller than a user-defined maximum time step length.

Different formulas can be used for the estimation of bedload transport capacity. The approaches of Rickenmann (2001), Wilcock and Crowe (2003) and Recking (2010) are implemented in sedFlow. The formula of Rickenmann (2001)

\footnotetext{
${ }^{1}$ When explicit kinematic-wave flow routing is used, the model does not check whether the calculated time step length is smaller than a user-defined maximum length, because the CFL criterion for the water flow velocity usually produces time step lengths which are considerably smaller than commonly used maxima.
}

modified for fractional transport was used here:

$\Phi_{\mathrm{bi}}=3.1 \cdot\left(\frac{D_{90}}{D_{30}}\right)^{0.2} \cdot \sqrt{\theta_{i, \mathrm{r}}} \cdot\left(\theta_{i, \mathrm{r}}-\theta_{c i, \mathrm{r}}\right) \cdot F r \cdot \frac{1}{\sqrt{s-1}}$,

with $q_{\mathrm{b}}=\Sigma q_{\mathrm{bi}}$.

Here $\Phi_{\mathrm{bi}}=\frac{q_{\mathrm{bi}}}{F_{i} \sqrt{(s-1) g D_{i}^{3}}}$ is the dimensionless bedload transport rate per grain-size fraction, $F_{i}$ is the relative portion compared to the total surface material with $D>2 \mathrm{~mm}$ of a grain-size fraction $i$ with $D_{i}$ as its mean diameter, $q_{\mathrm{bi}}$ is the volumetric bedload transport per grain-size fraction and unit channel width, $s=\frac{\rho_{\mathrm{s}}}{\rho}$ is the density ratio of solids $\rho_{\mathrm{s}}$ and the fluid $\rho, F r$ is the Froude number, $\theta_{i, \mathrm{r}}=\frac{r_{\mathrm{h}} S_{\mathrm{red}}}{(s-1) D_{i}}$ is the dimensionless bed shear stress and $S_{\text {red }}$ is the reduced energy slope according to Rickenmann and Recking (2011) and Nitsche et al. (2011). Here $D_{90}$ and $D_{30}$ are characteristic grain diameters, for which 90 or $30 \%$ of the local GSD is finer, and $q_{\mathrm{b}}$ is the volumetric bedload transport rate per unit channel width. The critical dimensionless bed shear stress at the initiation of transport $\theta_{c i}$ is modified by the so-called hiding function either in the form of a relatively simple power-law relation (Parker, 2008):

$\theta_{c i}=\theta_{c 50}\left(\frac{D_{i}}{D_{50}}\right)^{m}$

or in the form proposed by Wilcock and Crowe (2003):

$$
\begin{aligned}
& \theta_{c i}=\theta_{c 50} \cdot\left(\frac{D_{i}}{D_{\mathrm{m}}}\right)^{m_{\mathrm{wc}}} \\
& \quad \text { with } m_{\mathrm{wc}}=\frac{0.67}{1+\exp \left(1.5-\frac{D_{i}}{D_{\mathrm{m}}}\right)}-1 .
\end{aligned}
$$

Here $D_{50}$ and $D_{\mathrm{m}}$ are the median and geometric mean grain diameter of surface material, $m$ is an empirical hiding exponent and $m_{\mathrm{wc}}$ is the hiding exponent according to Wilcock and Crowe (2003). The empirical exponent $m$ ranges from 0 to -1 , where $m=-1$ corresponds to the socalled "equal mobility" case in which all grains start moving at the same dimensionful bed shear stress $\tau$, and $m=0$ corresponds to no influence by hiding at all. The critical dimensionless bed shear stress at initiation of transport $\theta_{c 50}$ is estimated based on the bed slope $S_{\mathrm{b}}$ with the empirical relation of Lamb et al. (2008) according to Eq. (10):

$\theta_{c 50}=0.15 \cdot S_{\mathrm{b}}^{0.25}$.

Within sedFlow a minimum value $\theta_{c 50 \text {, Min }}$ can be defined for $\theta_{c 50}$, as Eq. (10) results in unrealistically low $\theta_{c 50}$ values for small channel gradients. For consistency of calculations, $\theta_{c i, \mathrm{r}}=\theta_{c i}\left(\frac{S_{\mathrm{red}}}{S}\right)$ is used in Eq. (7).

\subsection{Model calibration and sensitivity calculations}

Using the data on channel geometry, GSD, and hydrology from the Brenno and Kleine Emme catchments, we ran 
the model sedFlow aiming to reproduce the observed bedload transport. The following criteria were applied to assess the agreement between simulation results and observations, which are stated in order of decreasing importance: (i) the input values, such as the local GSDs, should generally remain within the uncertainty range of observations. (ii) The input parameters, such as the threshold bed shear stress at the beginning of bedload motion, should vary within a plausible range. (iii) The simulated erosion and deposition should be as close as possible to the observed pattern. (iv) The simulated ABT should be as close as possible to the one reconstructed from field observations. (v) The GSDs at the end of the simulation should vary within a plausible range. In the calibration of this study, we examined these criteria (i-v) by visual inspection.

The calibration process consists of five steps. First, a hydraulic routing scheme is selected. Second, a bedload transport relation is selected. Third, the threshold for the initiation of motion is adjusted. Fourth, if the simple power-law hiding function of Eq. (8) is used, the exponent $m$ is adjusted as well. Fifth, some fine-tuning is made via local reach-scale adjustments. In general, the calibration parameters for bedload transport can be divided into three groups. The selection of the transport equation and the threshold for the initiation of motion $\theta_{c 50}$ (or $\theta_{c 50, \text { Min }}$ in combination with the relation of Lamb et al., 2008) are global calibration parameters, which determine the overall level of transport rate. The local GSDs and representative channel widths are local calibration parameters, which can be used to locally modify the transport rates and thus the along-channel distribution pattern of transport rates. Finally, the selection of the hiding function and the hiding exponent $m$, the method for the interaction between the active surface layer and the subsurface alluvium, and the thickness of the active surface layers form the remaining calibration parameters. To the authors' knowledge, there are no in-depth studies assessing the effects of these remaining parameters, which are hard to predict for a natural river system without a systematic sensitivity study.

In the first step of the calibration process of the presented study, the implicit kinematic wave hydraulic routing scheme was selected for the Kleine Emme, because the gentle slopes preclude the uniform discharge approach and the long simulated time period requires fast simulations. For the Brenno, the uniform discharge approach was selected, because the intense sediment inputs from the tributaries require the consideration of adverse slopes. In the fifth step of the calibration process, reach-scale adjustments have been made to the GSD in the Kleine Emme and to the representative channel width in the Brenno river. For the Kleine Emme, the representative channel width was well constrained, while measured GSD's were relatively poorly constrained because the riverbed is accessible only at a limited number of gravel bars. For the Brenno, the uncertainty about the effective channel width is relatively large along the depositional reaches in flatter areas, and for the calibration of the sedFlow simulations the mean channel width was adjusted primarily in these reaches. The corresponding simulation set-ups are summarised in Table 2. For the sediment exchange mechanism between the active surface layer and the subsurface alluvium, in the Brenno, we used a threshold-based interaction approach with 20 and $70 \mathrm{~cm}$ as thresholds for the active surface layer thickness. In the Kleine Emme, we used a shear-stress-based interaction approach in which the constant active surface layer thickness equals twice the local surface $D_{84}$ at the beginning of the simulation.

For the Brenno, the simulation of the calibration period was repeated using all three different hydraulic schemes and two flow-resistance relations, which are implemented in sedFlow. Comparing these simulation results allows us to study the influence of the hydraulic algorithm on the simulated bedload transport.

To explicitly study the influence of different time step lengths, we used a set-up in which the actual time step generally equals the user-defined maximum time step value ${ }^{2}$. We compared the simulation results for different maximum time steps ranging from $1 \mathrm{~min}$ to $1 \mathrm{~h}$. For any other simulation outside this time step comparison, we used a maximum time step of $15 \mathrm{~min}$ for the Kleine Emme and a maximum time step of $1 \mathrm{~h}$ for the Brenno. These two values have been selected in order to achieve reasonably short calculation times.

After the calibration exercise, the best-fit parameter set was used as a base for two sensitivity studies. For the first study, in each simulation, all parameters but one are set to their original best-fit values and the remaining parameter is increased and decreased by a certain fraction. In the following we will call this procedure a one-at-a-time range sensitivity study. We varied the parameters discharge, minimum threshold for the initiation of bedload motion $\theta_{c 50, \text { Min }}$, grain size and channel width by either plus or minus 10,20 and $30 \%$. The maximum variation of $30 \%$ fits the order of magnitude of the different uncertainties typically involved in bedload transport simulations. For example, discharge values are affected by the uncertainties of the rainfall-runoff simulations. The GSD of river reaches is measured at individual and accessible points and therefore cannot sufficiently capture the spatial variability of this parameter. The value of the minimal threshold for the initiation of bedload motion $\theta_{c 50, \text { Min }}$ may vary along the river length (we assumed a constant value for the best-case simulation) and, as described before, the effective channel width exhibits considerable uncertainty in depositional reaches. However, considering the more detailed knowledge of the system of the Kleine Emme, a reduced uncertainty of only plus or minus $20 \%$ is more appropriate than an uncertainty of $30 \%$ for discharge and channel width in this catchment.

\footnotetext{
${ }^{2}$ However, it cannot be excluded that in a few time steps another of the conditions for temporal discretisation (listed in Sect. 2.4) caused a different time step length.
} 
Table 2. Summary of calibration period simulations with different equation sets.

\begin{tabular}{lllllrr}
\hline Figure & River & Flow resistance & $\begin{array}{l}\text { Bedload } \\
\text { transport }\end{array}$ & $\begin{array}{l}\text { Threshold for } \\
\text { transport }\end{array}$ & $\begin{array}{r}\text { ABT- } \\
\text { RMSE }\end{array}$ & $\begin{array}{r}\text { ABT- } \\
\text { Nash-Sutcliffe }\end{array}$ \\
\hline 6 & Kleine Emme & $\begin{array}{l}\text { Manning- } \\
\text { Strickler-type }\end{array}$ & $\begin{array}{l}\text { Rickenmann (Eq. 7) } \\
\text { W and C hiding* }\end{array}$ & $\begin{array}{l}\text { Lamb et al. (2008) } \\
\theta_{c 50, \text { Min }}=0.06\end{array}$ & $7.83 \times 10^{3} \mathrm{~m}^{3}$ & 0.949 \\
7 & \multirow{2}{*}{ Brenno } & $\begin{array}{l}\text { Variable } \\
\text { power-law }\end{array}$ & $\begin{array}{l}\text { Rickenmann (Eq. 7) } \\
\text { no hiding }\end{array}$ & $\begin{array}{l}\text { Lamb et al. (2008) } \\
\theta_{c 50, \text { Min }}=0.1\end{array}$ & $18.0 \times 10^{3} \mathrm{~m}^{3}$ & 0.733 \\
\hline
\end{tabular}

* Wilcock and Crowe (2003) hiding (Eq. 9).

For the second sensitivity study, all possible combinations of maximum decreased $(-30 \%)$, best-fit and maximum increased $(+30 \%)$ values for all treated parameters were simulated $^{3}$. In the following we will call this a complete range sensitivity study. In this complete range sensitivity analysis, the sediment input volumes from the tributaries to the Brenno were varied as well by plus or minus $30 \%$.

Some model parameters described in the companion paper by Heimann et al. (2015) have not been included in the sensitivity analyses for the following reasons:

- For the exponent $e$ of the flow-resistance partitioning approach of Rickenmann and Recking (2011) and Nitsche et al. (2011), previous studies have shown that for various cases and conditions the value of 1.5 performed well in reproducing available observations (Nitsche et al., 2011). Therefore, we have not included $e$ in our sensitivity study and instead recommended the use of a default value of 1.5.

- The abrasion coefficient $\lambda$ of the equation of Sternberg (1875) is commonly only used in simulations of test reaches longer than $30 \mathrm{~km}$, as this is the minimum distance for $\lambda$ to have considerable influence.

- The hiding exponents $m_{\mathrm{wc}}$ and $m$ (Eqs. 8 and 9) do not fit in the concept of the presented sensitivity analysis, which is the variation of a best-fit value by a certain percentage. In addition, there are almost no field data providing guidance for suitable values of the hiding function for the coarser part of the GSD.

\section{Results}

\subsection{Simulations for the calibration period}

At the Kleine Emme, the simulated ABT shows agreement with the observed sediment budget (Fig. 6). Locally, how-

\footnotetext{
${ }^{3}$ In three simulations at the Kleine Emme with high $\theta_{c 50, \text { Min }}$, low discharge, coarse GSD and narrow, mean or wide channel widths, the river could not transport the bank erosion sediment inputs near $12 \mathrm{~km}$. This resulted in the creation of adverse slopes. Therefore, these three simulations have been excluded from the complete range sensitivity study.
}

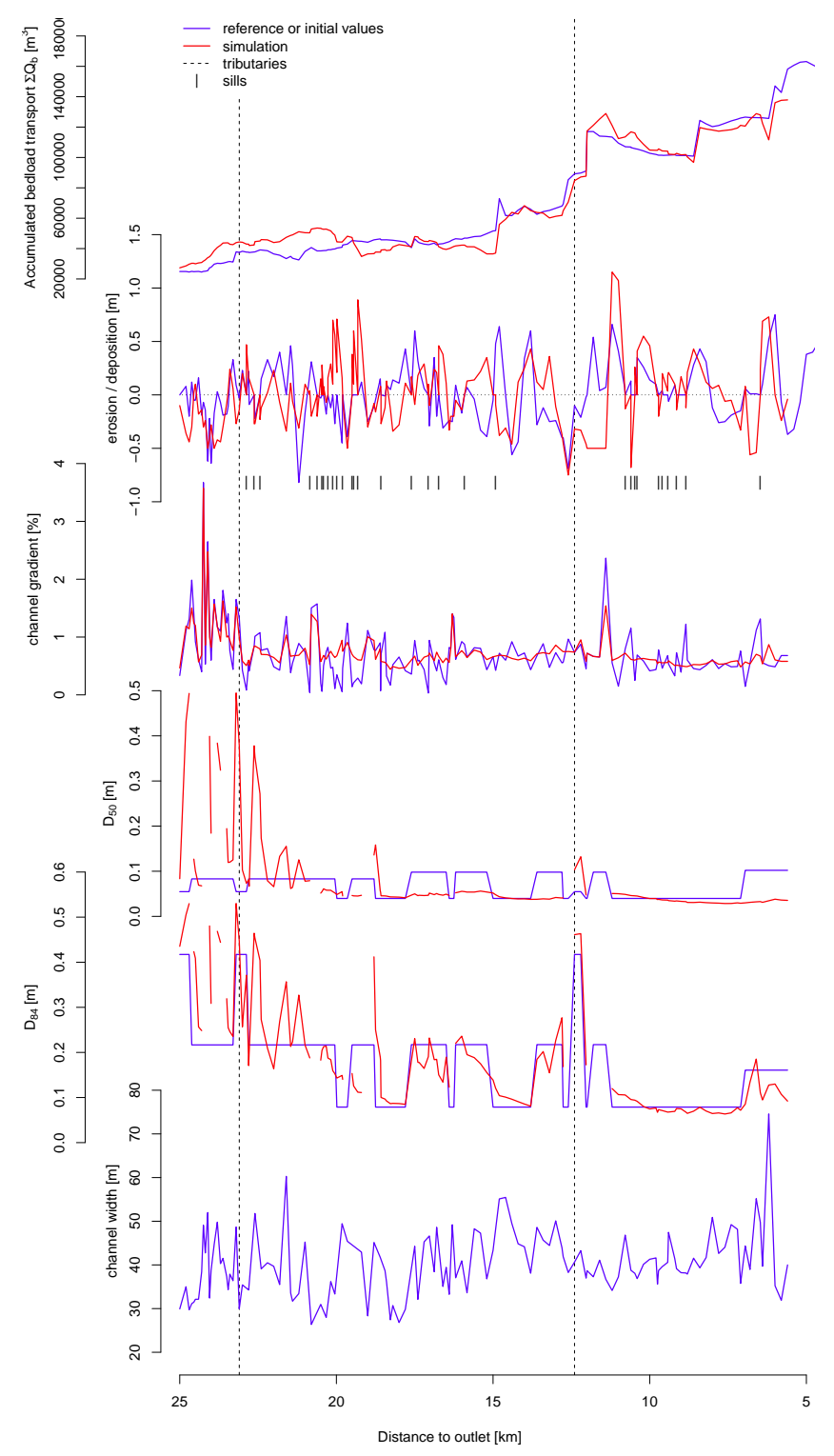

Figure 6. Comparison of predictions and observations related to bedload transport in the Kleine Emme for the period 2000-2005 (tributaries from up- to downstream: Fontanne, Rümlig). 


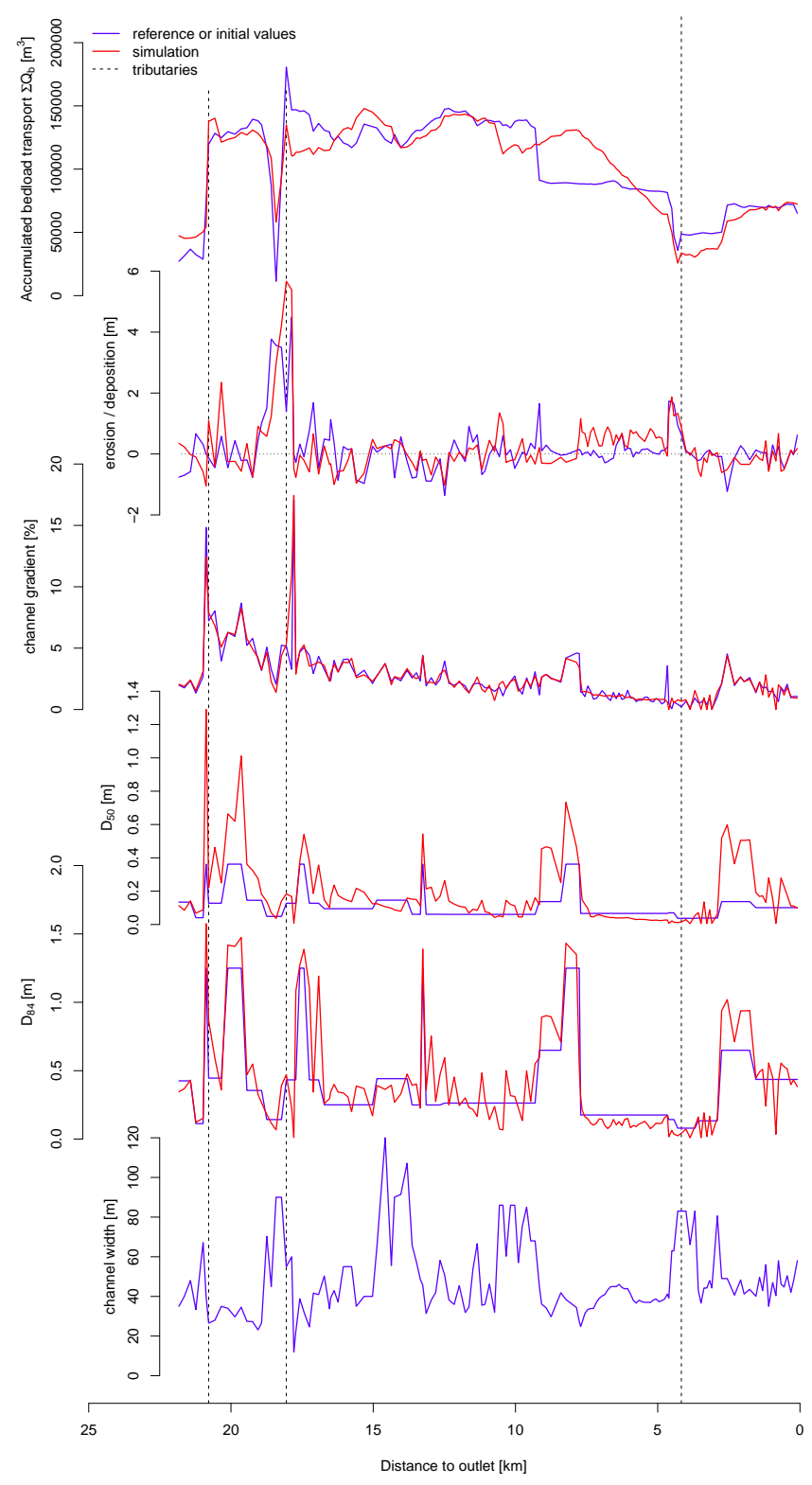

Figure 7. Comparison of predictions and observations related to bedload transport in the Brenno for the period 1999-2009 (tributaries from up- to downstream: Riale Riascio, Ri di Soi, Lesgiüna).

ever, simulations and observations of erosion and deposition can differ considerably. In the uppermost part down to $\sim 17 \mathrm{~km}$, peaks of very coarse GSDs are simulated. The gaps in the simulated GSD represent reaches in which the alluvial cover is washed out completely and the river runs over bedrock. Downstream of $\sim 17 \mathrm{~km}$, simulated final GSDs are close to the initial values.

At the Brenno, the simulation depicts well the interactions and qualitative transport behaviour in the vicinity of the tributaries Riale Riascio and Ri di Soi (Fig. 7). Downstream of the anthropogenic excavation at $10 \mathrm{~km}$, which is not considered in the simulation, the model exhibits an overall depo- sitional trend. The low sediment transport from 4.5 to $3 \mathrm{~km}$ due to a locally increased channel width is well reflected in the simulations. Except for the depositional trend from $\sim 8$ to $\sim 4.5 \mathrm{~km}$ (which did not occur in reality because substantial sediment volume was anthropogenically excavated from this reach) the simulated erosion and deposition show good agreement with the observations. In reaches with larger channel gradients the model produces a coarsening of GSDs. Apart from these reaches, simulated final GSDs are close to their initial values.

In both rivers, the model tends to smoothen spatially varying channel gradients (Figs. 6 and 7). Furthermore, in both rivers, the GSDs evolve over the course of a model run such that the final GSDs can be interpreted as a function of bed slope (coarse grains in steep sections), channel width (coarse grains in narrow sections) and channel network (coarse grains at confluences with steep tributaries). The channel width is not modified during the simulations.

The simulations of the Brenno suggest an intense backward migrating erosion of the knickpoints at the confluences with debris flow tributaries, but this is not observed in the field. This erosion can be prevented in the simulations either by limiting the alluvium thickness and thus potential erosion depth, or by adding coarse blocks to the local GSD, which have not been captured in the transect pebble count, or by introducing a maximum Froude number limit in the flow resistance and drag-force partitioning calculations.

In both rivers, early in the course of a simulation the model tends to adjust surface GSDs, which stay roughly the same for the rest of the simulation and which therefore seem to be stable under the local conditions (i.e. local slope, channel width, subsurface GSD and discharge pattern).

In the Kleine Emme, the variation of maximum time step length caused differences in the modelled erosion and deposition only at a few locations. This results in small differences in modelled ABT along the complete river length (Fig. 10). In the Brenno, long maximum time step lengths caused an underestimation of the depositional trend from 6 to $5 \mathrm{~km}$. Downstream of this position, the underestimation of deposition resulted in an overestimation of simulated ABT (Fig. 11).

\subsection{Sensitivity analyses}

The local sensitivity analysis (Fig. 8) shows that variations in input discharge and GSDs have a large influence on the resulting $\mathrm{ABT}$ in both rivers. The impact of variations of the minimum value for the threshold dimensionless shear stress at the initiation of bedload motion $\left(\theta_{c 50, \mathrm{Min}}\right)$ ranges from low in the Brenno to high in the Kleine Emme. In general, relative output variations are larger in the Kleine Emme than in the Brenno. However, this statement is only true when uncertainties of $30 \%$ are assumed for both rivers. The difference in trend is less pronounced when the smaller uncertainties of 


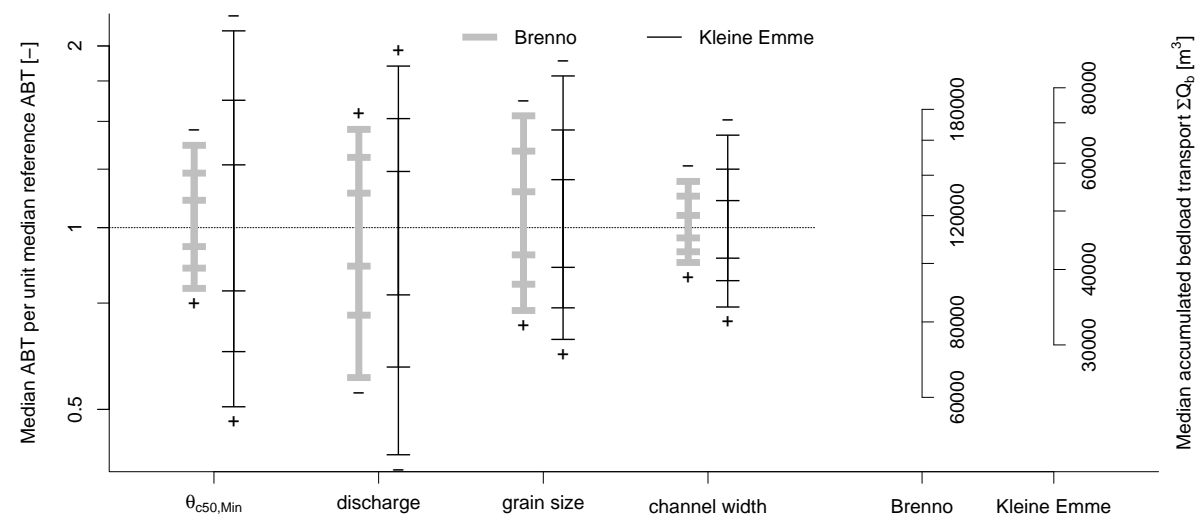

Figure 8. Simulation sensitivity with respect to simulated accumulated bedload transport (ABT) for different input parameters. The horizontal line represents the reference best-fit simulations of Figs. 6 and 7. The tick marks at the vertical bars display the simulation results for input parameter variations of either plus or minus 10,20, and $30 \%$. Plus or minus signs at the end of the bars indicate whether the input parameter was increased (plus) or decreased (minus).

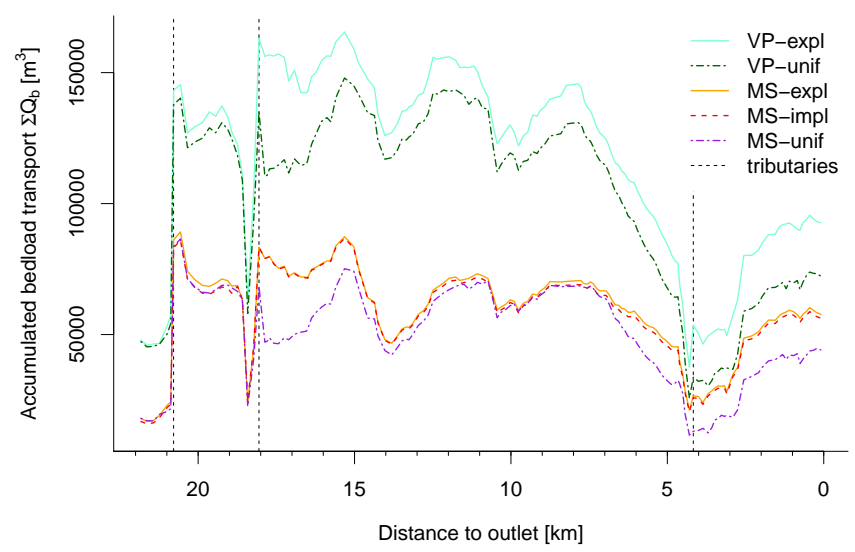

Figure 9. Comparison of simulated accumulated bedload transport in the Brenno for different combinations of flow-routing schemes and flow-resistance relations. Two flow-resistance relations are shown: the variable power relation given in Eq. (5) (denoted VP) and the grain-size-dependent Manning-Strickler relation given in Eq. (6) (denoted MS). Three flow-routing schemes are shown: explicit kinematic wave (denoted expl), implicit kinematic wave (denoted impl) and uniform discharge (denoted unif). The VP-unif curve (green dot-dashed line) is the same as the red line in the top panel of Fig. 7 and displays the reference best-fit simulation.

$20 \%$ for discharge and channel width at the Kleine Emme are taken into account.

Comparing the three implemented hydraulic schemes, the explicit and implicit hydraulic flow routing produce practically identical results and the differences to using an uniform discharge approach are small in the Brenno catchment (Fig. 9). In contrast, there is a considerable difference in ABT between the simulations based on the two different flowresistance relations (Fig. 9).

As a main result of the complete range sensitivity study, the variation of input values caused considerable variation in the simulated ABT, but caused very little variability in the simulated erosion and deposition (Figs. 12 and 13).

\section{Discussion}

\subsection{Simulations for the calibration period}

Bedload transport and morphodynamic observation of both rivers can be reproduced with plausible parameter set-ups (Table 2 and Figs. 6 and 7). At the Kleine Emme the simulated absolute values of net erosion and net deposition at the end of the calibration period are small and thus close to the noise of the measurements. Therefore, the differences between observed and simulated morphodynamics may be partly explained as noise. The simulated peaks of very coarse GSD in the upper part of the Kleine Emme are due to the small alluvium thickness, which is in some places washed out completely (or nearly so). If only a few coarse grains are left in a reach, they will produce extremely coarse grainsize percentiles. At the Brenno, the deposition from $\sim 8$ to $\sim 4.5 \mathrm{~km}$ (Fig. 7), which substitutes for the unconsidered excavation, appears as a plausible behaviour of the river without any anthropogenic interventions. Coarsening at reaches with increased channel gradient is plausible as well. At the Brenno, the minimum threshold dimensionless shear stress $\theta_{c 50, \text { Min }}$ for the initiation of bedload motion has been calibrated to a value of 0.1 (Table 2). This corresponds to the findings of Lamb et al. (2008) and Bunte et al. (2013), who showed that in mountain rivers $\theta_{c}$ may well assume values in this order of magnitude.

The good agreement of bedload transport simulations and observations may be surprising, given that the natural system is complex and the model representation is relatively simple, with only a few parameters for calibration. The selected transport equation and threshold for the initiation of motion determine the average level of transport volumes. 


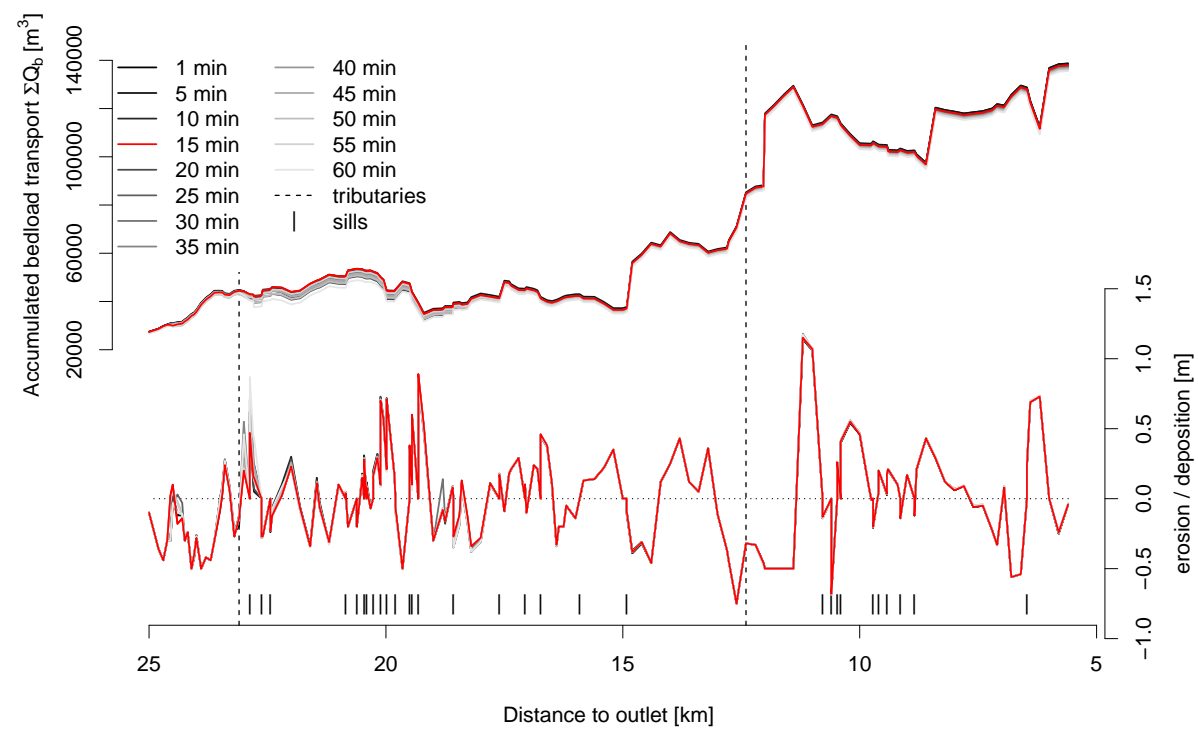

Figure 10. Comparison of simulated accumulated bedload transport and erosion and deposition in the Kleine Emme for different maximum time step lengths denoted in the plot legend. The maximum time step length value, which has been used for any other simulation in the Kleine Emme (e.g. Fig. 6), is displayed in red.

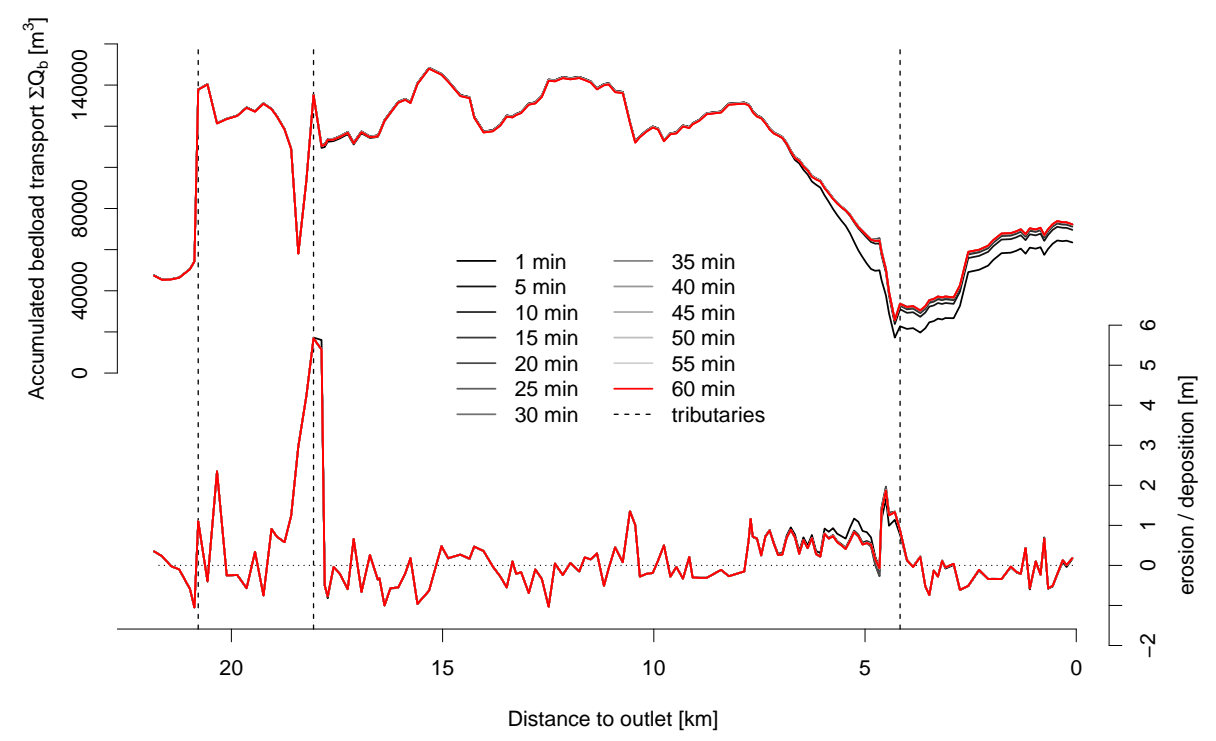

Figure 11. Comparison of simulated accumulated bedload transport and erosion and deposition in the Brenno for different maximum time step lengths denoted in the plot legend. The maximum time step length value, which has been used for any other simulation in the Brenno (e.g. Fig. 7), is displayed in red.

The selected hiding function locally modulates the calculated volumes and in particular influences the evolution of the GSD. Despite its simplicity, the described modelling framework appears to be adequate for a quantitative description of bedload transport processes, as suggested by the reasonable agreement of simulation and observation.

The better agreement of simulated and reference ABT at the Kleine Emme compared to the Brenno is not surprising. At the Kleine Emme, there are no debris flow inputs, the influence of tributaries is limited and the sediment outflow is known. The Kleine Emme is a well-defined system with low uncertainties and thus is ideal for simulation. In addition, spatially distributed calibration was applied more extensively to the Kleine Emme than to the Brenno. For the Brenno, spatially distributed calibration was performed by adjusting the width of the channel. This was done only at depositional reaches, which entail considerable uncertainty in the representative substitute channel width and which cor- 


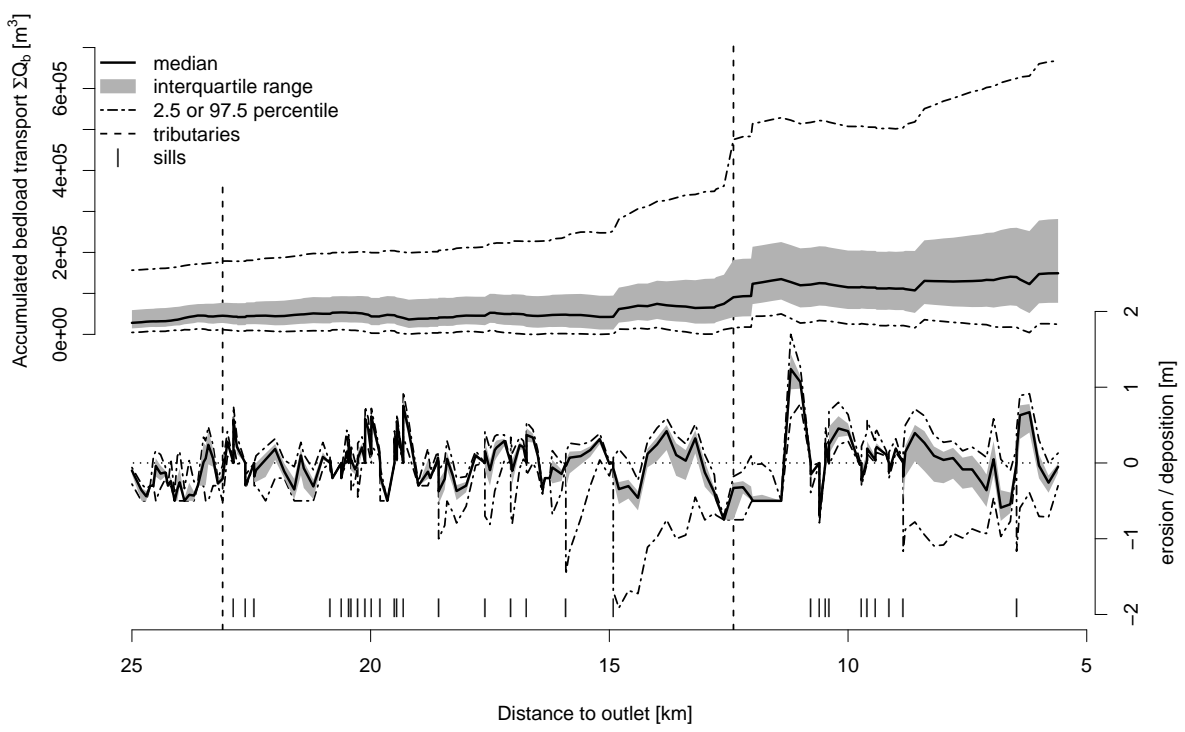

Figure 12. Output variability within the sensitivity study for the Kleine Emme.

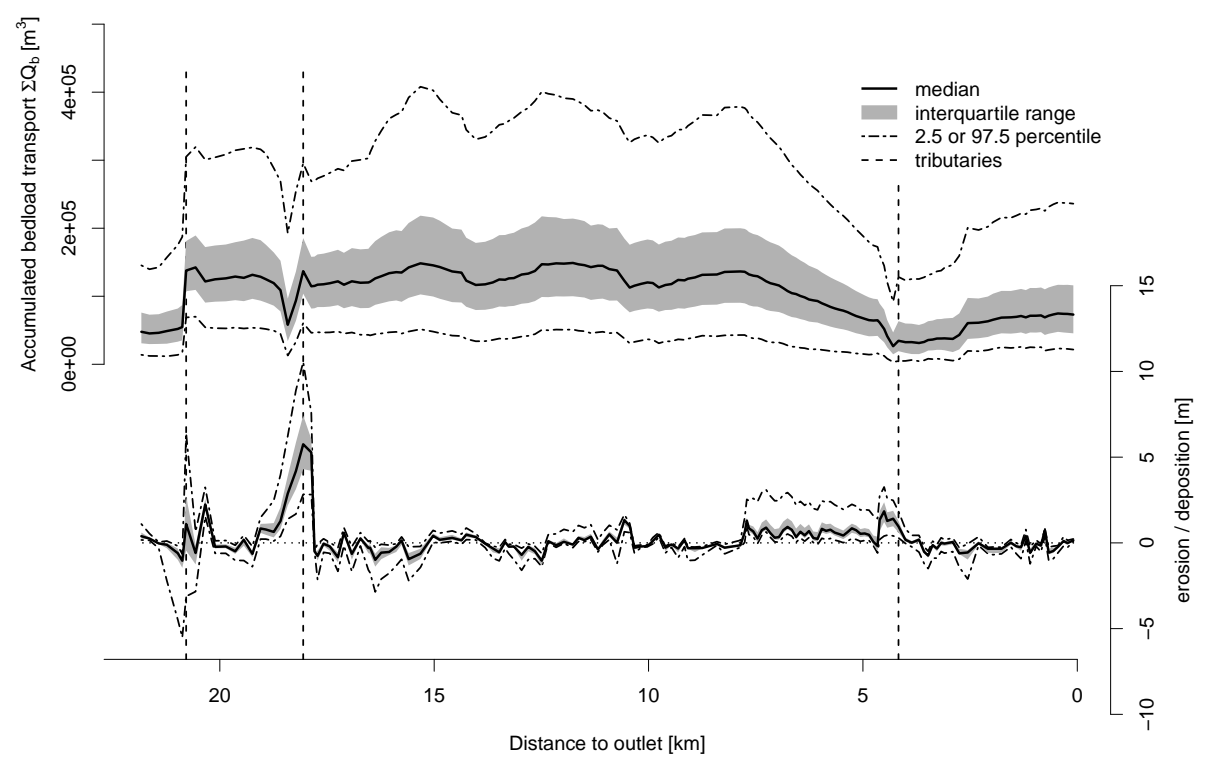

Figure 13. Output variability within the sensitivity study for the Brenno.

respond to only ca. $30 \%$ of the total study-reach length. In contrast, at the Kleine Emme, spatially distributed calibration was performed by adjusting local GSDs along the complete study reach. This more extensive, spatially distributed calibration at the Kleine Emme partly also explains the better agreement of simulated and reference $\mathrm{ABT}$ at the Kleine Emme compared to the Brenno.

Few studies (Lopez and Falcon, 1999; Chiari and Rickenmann, 2011; Mouri et al., 2011) have performed a spatially distributed comparison of simulations and field observations, similar to what is presented in this article. However, these studies focused on shorter river lengths than the Brenno and the Kleine Emme. Lopez and Falcon (1999) performed a lumped calibration by simply multiplying calculated transport rates by four. In all aforementioned studies, the models have been calibrated but not independently validated (similarly to the present investigation). This contrasts with approaches used in other research fields such as hydrology (Beven and Young, 2013), where it is common practice to perform a calibration and a validation separately. The lack of independent validation is mainly due to the marked scarcity of available field data on bedload transport. Other studies compared simulation results against point data derived from field observations (Hall and Cratchley, 2006; Li et al., 2008), 


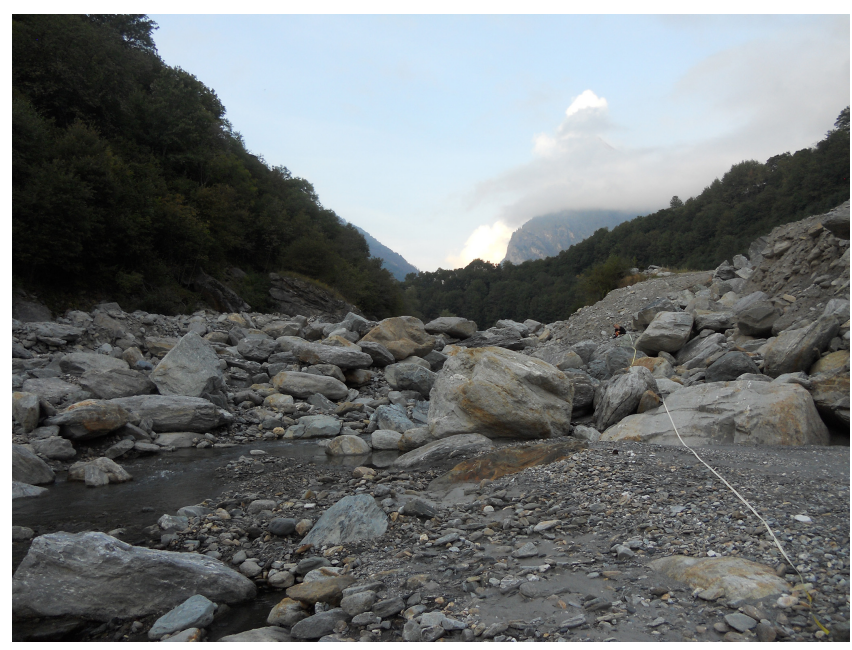

Figure 14. River bed of the Brenno at the confluence with the Riale Riascio (at $20.8 \mathrm{~km}$, Fig. 7) exhibiting blocks with diameters of up to $2 \mathrm{~m}$.

against analytic considerations (García-Martinez et al., 2006) or against a combination of field data and analytical results along with additional flume experiment data and results from other models (Papanicolaou et al., 2004). Many studies discuss model behaviour without any explicit comparison between that behaviour and observational data (Lopez and Falcon, 1999; Papanicolaou et al., 2004; Hall and Cratchley, 2006; Li et al., 2008; García-Martinez et al., 2006; Radice et al., 2012).

The simulated GSDs might be seen as a proxy for GSDs which are consistent with the local slope, channel geometry and discharge pattern. This idea is rather attractive, as the model would use variables with a low uncertainty to estimate the local GSD, which is associated with a relatively large uncertainty. Unfortunately, the simulated surface GSD also depends on the subsurface GSD, and on the algorithm regulating the exchange between the surface and subsurface layers (for details see Heimann et al., 2015). In any case, the simulated surface GSD is consistent with local conditions. However, the simulated surface GSD is influenced either by an unrealistically small interaction between surface and subsurface, or by a highly uncertain and possibly incorrect subsurface GSD. Nevertheless, these simulated GSDs will be internally consistent with the other assumptions in the model and thus may have the potential to serve as input for calibration exercises and follow-up studies. A detailed investigation of this topic is beyond the scope of this article.

The simulated erosion of knickpoints in the Brenno was not observed in the field and is thus unrealistic. This suggests that large blocks, which are present in these reaches, but which have not been captured by the transect pebble counts, are important to stabilise the bed. The influence of large blocks also explains why the GSD at these positions had to be coarsened to achieve realistic model behaviour. In addi- tion, the simulated GSDs coarsened even further. Both the unrealistic erosion and the need for coarsened GSDs point to the limitations of a volumetric percentile grain diameter to serve as a proxy for channel roughness. Flow-resistance estimation depends on the representative grain diameter $D_{84}$ in both the Manning-Strickler and variable power equation formulations (Ferguson, 2007). However, even a few large blocks, possibly at percentiles higher than 84 , can heavily influence the properties of the flow. The problems of a single representative grain-size percentile used as a proxy for bed roughness become more severe in the case of a discontinuous GSD, for example if the coarse blocks originate from rock fall and thus from a different source than the alluvial gravel. In such cases, any percentile diameter will considerably over- or underestimate the roughness, if its value falls in the gap of the discontinuous GSD. Coarse blocks are also a problem for the general concept of a volumetric percentile. Only a small fraction of the volume of a large block belongs to the surface layer of the river bed, which is assumed to define its roughness. Large parts of such blocks protrude into the deeper alluvium or into the water flow not belonging to the surface layer (or even into the air above the flow). Therefore, the volumetric contribution of such blocks to the surface layer is hard to determine. These issues are reflected in conceptual models for flow resistance, such as the ones of Yager et al. (2007) or Nitsche et al. (2012), which consider large blocks explicitly, e.g., in terms of a surface block density. In a recent study, Ghilardi (2013) suggested that the protrusion height of large blocks into the flow could be used as a potential proxy for flow resistance. Based on this approach, the visual appearance of the Brenno river bed (Fig. 14) suggests a roughness of about $1-2 \mathrm{~m}$. This value is of the same order of magnitude as the $D_{84}$ of the coarsened GSDs (Fig. 7), which we used as a roughness proxy in our simulations. It is further supported by additional area block counts in the Brenno, which showed that grains with a diameter smaller than $1 \mathrm{~m}$ only make up $90 \%$ of the surface layer's sediment volume or even only $75 \%$ at the confluence with the Riale Riascio (Fig. 14). These blocks observed in the field dominate the macro-roughness. Since $D_{84}$ is selected to represent macro-roughness, the block counts support the $D_{84}$ values which are used in the simulations, and which are of the same order of magnitude as the observed block diameters.

To assess the influence of time step length, the userdefined maximum time step length was varied between $1 \mathrm{~min}$ and $1 \mathrm{~h}$. In the Kleine Emme, the influence of time step length is negligible compared to the overall uncertainty of bedload transport simulations (Fig. 10). In the Brenno, the effect of large maximum time step lengths is spatially limited and well defined (Fig. 11) and thus can be easily considered in the interpretation of the simulation results. 


\subsection{Sensitivity analyses}

The limitations of simple one-at-a-time sensitivity studies for the analysis of non-linear processes are well known (Saltelli et al., 2006). However, an adequate global sensitivity analysis, in which the complete parameter space is covered, would go beyond the scope of this article.

As shown in Fig. 8 the model reacts differently to input changes, depending on which parameter is modified. The model's reaction to input changes also depends on the current river setting. For example, the relative variability and thus uncertainty of model outputs is generally larger in the Kleine Emme as compared to the Brenno. This may be partially due to the fact that the volumes of transported sediment are generally smaller in the Kleine Emme as compared to the Brenno. However, the output uncertainty can be partially compensated by better-supported knowledge and thus higher confidence in the inputs (reduced uncertainty of only plus or minus $20 \%$ for discharge and channel width at the Kleine Emme). Interestingly, even the order of parameter sensitivities may change depending on the current river setting. For example, the reaction to changes in the minimum threshold for the initiation of bedload transport $\theta_{c 50 \text {, Min }}$ differs considerably for the two rivers. In the Kleine Emme, the uncertainty of this parameter seems to be responsible for a large part of the model output uncertainty. In contrast, in the Brenno $\theta_{c 50, \text { Min }}$ plays a rather subordinate role.

In the complete range sensitivity study (Figs. 12 and 13) all input variations have been applied to the complete length of the river. This may explain why the simulated erosion and deposition show only limited variation compared to the simulated ABT. Erosion and deposition are a function of changes of channel properties (gradient, width, GSD, inputs) along the river. Applying the input variation to the complete length of the river keeps the relative changes of channel properties the same. Even though bedload transport is not a linear system, the input variation on the complete length of the river did not cause considerable variation of simulated erosion and deposition. Nevertheless, the sensitivity study with its highly variable ABT and almost constant morphodynamics stresses the uncertainty of ABT estimates that are only derived from morphologic changes. These simulation results support previous studies that have discussed this issue (Kondolf and Matthews, 1991; Reid and Dunne, 2003; Erwin et al., 2012). This is especially important because ABT plots are very common for the description of bedload transport in applied engineering practice and are even recommended by authorities (e.g. Schälchli and Kirchhofer, 2012).

As is illustrated in Fig. 9 for the Brenno river, the two different flow-resistance relations produce considerably different values of simulated ABT. This further stresses the limitations of Manning-Strickler-type flow-resistance relations in steep mountain streams, as discussed in Rickenmann and Recking (2011). In contrast, the three different flow-routing schemes predict similar transported bedload volumes in the
Brenno river (Fig. 9). Differences can be neglected when compared to the overall uncertainties of bedload transport simulations. Therefore, the influence on the model outputs does not constitute a preference for any of the hydraulic schemes and any scheme can be selected based on its characteristics. If adverse slopes occur or if the variable power equation flow resistance, which is more suitable for shallow flow in steeper channels, is to be used without slowing down the calculations, one may select the uniform discharge approach. If one needs neither the ability to deal with adverse slopes nor the use of the variable power equation flow resistance, one may select the implicit kinematic wave routing, as it provides a routing of discharge. If a variable power equation approach is to be combined with a routing of discharge, one may select the explicit kinematic wave routing, even though this option is not recommended due to its long calculation times.

\section{Conclusions}

In this article, we used the model sedFlow to calculate bedload transport in two Swiss mountain rivers. sedFlow is a tool designed for the simulation of bedload dynamics in mountain streams. Observations of bedload transport in these two rivers have been successfully reproduced with plausible parameter settings. The results of the one-at-a-time range sensitivity analysis have shown that a defined change of an input parameter produces larger relative changes of output sediment transport rates in the Kleine Emme as compared to the Brenno, which may be due to the generally smaller transport rates at the Kleine Emme. Simulation results highlighted the problems that can arise because traditional flow-resistance estimation methods fail to account for the influence of large blocks. As an important result of our study, we conclude that a very detailed and sophisticated representation of hydraulic processes is apparently not necessary for a good representation of bedload transport processes in steep mountain streams. Both uniform flow routing and kinematic wave routing performed well in simulating field observations related to bedload transport. Moreover, it has been shown that bedload transport events with widely differing accumulated bedload transport (ABT) may produce identical patterns of erosion and deposition. This highlights the uncertainty in ABT estimates that are derived only from morphologic changes. This proof-of-concept study demonstrates the usefulness of sedFlow for a range of practical applications in alpine mountain streams. 


\section{Appendix A}

Table A1. Notation.

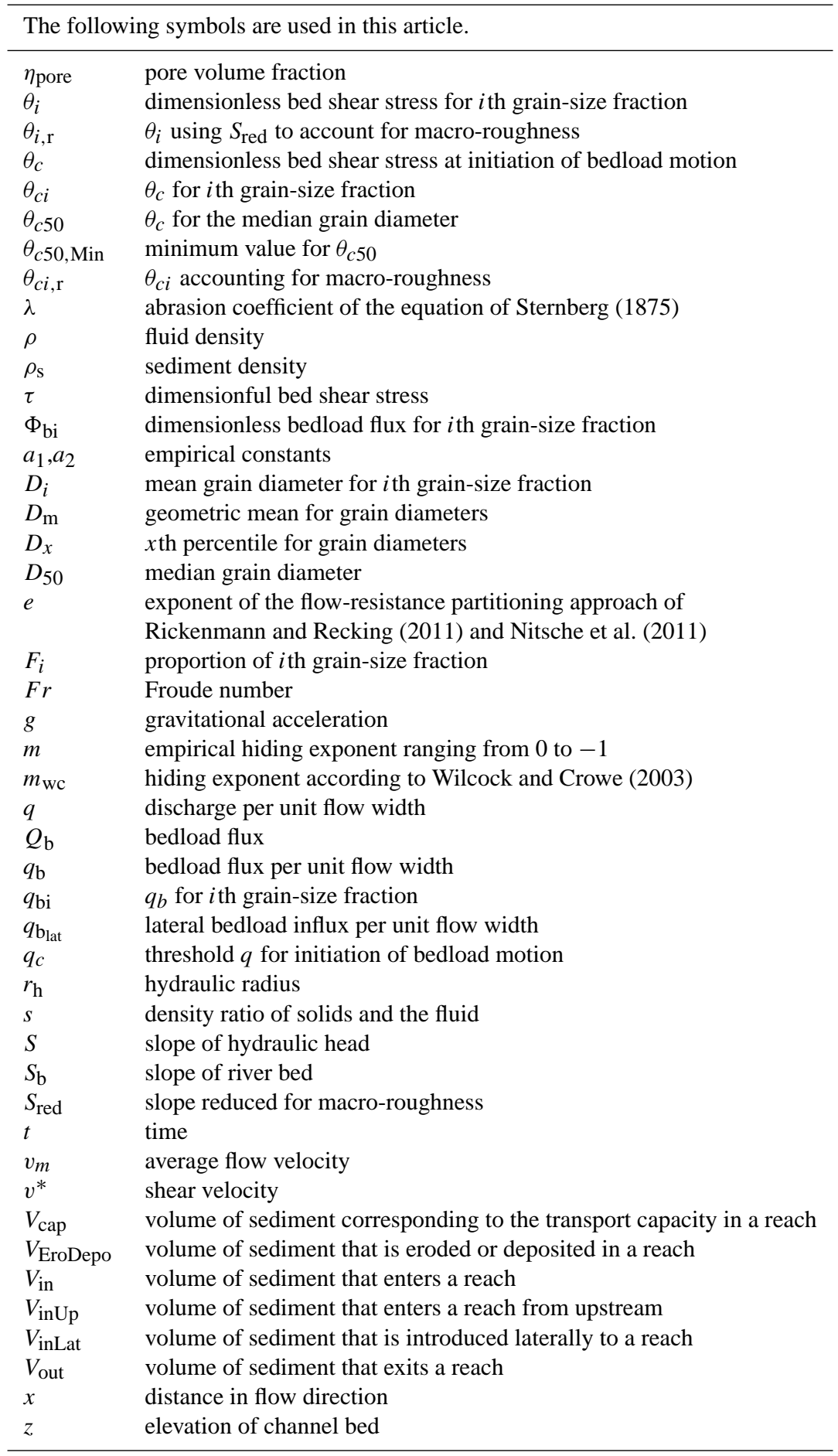


Acknowledgements. We are grateful to Christa Stephan (project thesis ETH/WSL), Lynn Burkhard (MSc thesis ETH/WSL), Anna Pöhlmann (WSL), Claudia Bieler (MSc thesis ETH/WSL) and Christian Greber (MSc thesis ETH/WSL) for their contributions to the development and application of sedFlow. Special thanks to Massimiliano Zappa for his PREVAH support and the hydrologic input data. We thank the Swiss National Science Foundation for funding this work in the framework of the NRP 61 project "Sedriver" (SNF grant no. 4061-125975/1/2). The simulations in the Brenno river were also supported by the BAFU (GHO) project "Feststofftransport in Gebirgs-Einzugsgebieten" (contract no. 11.0026.PJ/K154-7241) of the Swiss Federal Office for the Environment. Jeff Warburton and an anonymous referee provided thoughtful and constructive suggestions to improve this manuscript.

Edited by: D. Parsons

\section{References}

Anastasi, G.: Geschiebeanalysen im Felde unter Berücksichtigung von Grobkomponenten. Mitteilung Nr. 70. Versuchsanstalt für Wasserbau, Hydrologie und Glaziologie, ETH Zurich, Zurich, 99p., 1984.

Badoux, A., Andres, N., and Turowski, J. M.: Damage costs due to bedload transport processes in Switzerland, Nat. Hazards Earth Syst. Sci., 14, 279-294, doi:10.5194/nhess-14-279-2014, 2014.

Bathurst, J. C., Bovolo, C. I., and Cisneros, F.: Modelling the effect of forest cover on shallow landslides at the river basin scale, Ecol. Eng., 36, 317-327, doi:10.1016/j.ecoleng.2009.05.001, 2010.

Beffa, C.: 2D-Simulation der Sohlenreaktion in einer Flussverzweigung, Österreichische Wasser- und Abfallwirtschaft, 42, 1-6, 2005.

Beven, K. and Young, P.: A guide to good practice in modeling semantics for authors and referees, Water Resour. Res., 49, 50925098, doi:10.1002/wrcr.20393, 2013.

Bhowmik, N. G., Tsai, C., Parmar, P., and Demissie, M.: Case study: application of the HEC-6 model for the main stem of the Kankakee River in Illinois, J. Hydraul. Eng.-ASCE, 134, 355366, doi:10.1061/(ASCE)0733-9429(2008)134:4(355), 2008.

Bunte, K., Abt, S. R., Potyondy, J. P., and Swingle, K. W.: A comparison of coarse bedload transport measured with bedload traps and Helley-Smith samplers, Geodin. Acta, 21, 53-66, doi:10.3166/ga.21.53-66, 2008.

Bunte, K. B., Abt, S. R., Swingle, K. W., Cenderelli, D. A., and Schneider, J. M.: Critical Shields values in coarsebedded steep streams, Water Resour. Res., 49, 1-21, doi:10.1002/2012WR012672, 2013.

Chiari, M. and Rickenmann, D.: Back-calculation of bedload transport in steep channels with a numerical model, Earth Surf. Proc. Land., 36, 805-815, doi:10.1002/esp.2108, 2011.

Chiari, M., Friedl, K., and Rickenmann, D.: A one-dimensional bedload transport model for steep slopes, J. Hydraul. Res., 48, 152160, doi:10.1080/00221681003704087, 2010.

Courant, R., Friedrichs, K., and Lewy, H.: Über die partiellen Differenzengleichungen der mathematischen Physik, Math. Ann., 100, 32-74, doi:10.1007/BF01448839, 1928.
Doten, C. O., Bowling, L. C., Lanini, J. S., Maurer, E. P., and Lettenmaier, D. P.: A spatially distributed model for the dynamic prediction of sediment erosion and transport in mountainous forested watersheds, Water Resour. Res., 42, W04417, doi:10.1029/2004WR003829, 2006.

Erwin, S. O., Schmidt, J. C., Wheaton, J. M., and Wilcock, P. R.: Closing a sediment budget for a reconfigured reach of the Provo River, Utah, United States, Water Resour. Res., 48, W10512, doi:10.1029/2011WR011035, 2012.

Faeh, R., Mueller, R., Rousselot, P., Vetsch, D., Volz, C., Vonwiller, L., Veprek, R., and Farshi, D.: System manuals of BASEMENT. vol 2.2., VAW, ETH Zurich, Switzerland, available at: www.basement.ethz.ch (last access: 15 July 2014), 2011.

Fehr, R.: A method for sampling very coarse sediments in order to reduce scale effects in movable bed models, in: Proc. Symp. Scale effects in modelling sediment transport phenomena, Toronto, IAHR, Delft, 383-397, 1986.

Fehr, R.: Geschiebeanalysen in Gebirgsflüssen. Mitteilung Nr. 92. Versuchsanstalt für Wasserbau, Hydrologie und Glaziologie, ETH Zurich, Zurich, 139p., 1987.

Ferguson, R.: Flow resistance equations for gravel- and boulder-bed streams, Water Resour. Res., 43, W05427, doi:10.1029/2006WR005422, 2007.

Ferguson, R. I., Church, M., and Weatherly, H.: Fluvial aggradation in Vedder River: Testing a one-dimensional sedimentation model, Water Resour. Res., 37, 3331-3347, doi:10.1029/2001WR000225, 2001.

Flussbau AG: Geschiebetransport im Brenno. Einfluss der Murgangablagerung aus dem Ri di Soi, Tech. rep., Reppublica e Cantone Ticino - Divisione delle costruzioni - Ufficio dei corsi d'acqua, 2003 (unpublished report).

Flussbau AG: Revitalisierung von Auenökosystemen (Risanamento dei Ecosistemi Alluvionali) Fachbericht Morphologie und Geschiebe, Tech. rep., Reppublica e Cantone Ticino - Dipartimento del Territorio - Consorzio Risanamento Ecosistemi Alluvionali, 2005 (unpublished report).

Flussbau AG: Ereignisanalyse Hochwasser 2005 - Seitenerosion, Tech. rep., Swiss Federal Office for the Environment FOEN, 2009 (unpublished report).

García-Martinez, R., Espinoza, R., Valeraa, E., and González, M.: An explicit two-dimensional finite element model to simulate short- and long-term bed evolution in alluvial rivers, J. Hydraul. Res., 44, 755-766, doi:10.1080/00221686.2006.9521726, 2006.

Geoportal Kanton Luzern: available at: www.geo.lu.ch/map/ gewaessernetz (last access: 27 August 2013), 2013.

Ghilardi, T.: Intense sediment transport and flow conditions in steep mountain rivers considering the large immobile boulders, Ph.D. thesis, École polytechnique fédérale de Lausanne, 2013.

Gray, J. R., Laronne, J. B., and Marr, J. D.: Bedload-Surrogate Monitoring Technologies, Tech. rep., US Geological Survey Scientific Investigations Report 2010-5091, available at: http://pubs. usgs.gov/sir/2010/5091 (last access: 15 July 2014), 2010.

Habersack, H., Hengl, M., Huber, B., Lalk, P., and Tritthart, M. (Eds.): Fließgewässermodellierung - Arbeitsbehelf Feststofftransport und Gewässermorphologie, Austrian Federal Ministry of Agriculture, Forestry, Environment and Water Management and Österreichischer Wasser- und Abfallwirtschaftsverband ÖWAV, Vienna, 2011. 
Hall, G. and Cratchley, R.: Sediment erosion, transport and deposition during the July 2001 Mawddach extreme flood event, in: Sediment Dynamics and the Hydromorphology of Fluvial Systems, Dundee, UK, July, 136-147, 2006.

Heimann, F. U. M., Rickenmann, D., Turowski, J. M., and Kirchner, J. W: sedFlow - a tool for simulating fractional bedload transport and longitudinal profile evolution in mountain, Earth Surf. Dynam., 3, 15-35, doi:10.5194/esurf-3-15-2015, 2015.

Hunziker, Zarn \& Partner AG: Kleine Emme, Geschiebehaushaltstudie. Abschnitt Fontanne bis Reuss, Tech. rep., by order of Kanton Luzern Dienststelle Verkehr und Infrastruktur, Aarau, Switzerland, 2009.

Hunzinger, L. and Krähenbühl, S.: Sohlenveränderungen und Geschiebefrachten, in: Ereignisanalyse Hochwasser 2005. Teil 2 - Analyse von Prozessen, Massnahmen und Gefahrengrundlagen, edited by: Bezzola, G. R. and Hegg, C., Swiss Federal Office for the Environment FOEN and Swiss Federal Research Institute WSL, Chap. 4.2, 118-125, Berne, Switzerland, 2008.

Jaeggi, M.: The floods of August 22-23, 2005, in Switzerland: some facts and challenges, in: Gravel-Bed Rivers VI: From Process Understanding to River Restoration, edited by: Habersack, H., Piégay, H., and Rinaldi, M., Elsevier, 587-604, Amsterdam, The Netherlands, 2008.

Kondolf, G. M. and Matthews, W. V. G.: Unmeasured residuals in sediment budgets: a cautionary note, Water Resour. Res., 27, 2483-2486, doi:10.1029/91WR01625, 1991.

Lamb, M. P., Dietrich, W. E., and Venditti, J. G.: Is the critical Shields stress for incipient sediment motion dependent on channel-bed slope?, J. Geophys. Res., 113, F02008, doi:10.1029/2007JF000831, 2008.

Li, S. S., Millar, R. G., and Islam, S.: Modelling gravel transport and morphology for the Fraser River Gravel Reach, British Columbia, Geomorphology, 95, 206-222, doi:10.1016/j.geomorph.2007.06.010, 2008.

Liu, Z. and Todini, E.: Towards a comprehensive physically-based rainfall-runoff model, Hydrol. Earth Syst. Sci., 6, 859-881, doi:10.5194/hess-6-859-2002, 2002

Lopez, J. L. and Falcon, M. A.: Calculation of bed changes in mountain streams, J. Hydraul. Eng.-ASCE, 125, 263-270, doi:10.1061/(ASCE)0733-9429(1999)125:3(263), 1999.

Lukey, B., Sheffield, J., Bathurst, J., Hiley, R., and Mathys, N.: Test of the SHETRAN technology for modelling the impact of reforestation on badlands runoff and sediment yield at Draix, France, J. Hydrol., 235, 44-62, doi:10.1016/S00221694(00)00260-2, 2000.

Mouri, G., Shiiba, M., Hori, T., and Oki, T.: Modeling reservoir sedimentation associated with an extreme flood and sediment flux in a mountainous granitoid catchment, Japan, Geomorphology, 125, 263-270, doi:10.1016/j.geomorph.2010.09.026, 2011.

Nitsche, M., Rickenmann, D., Turowski, J. M., Badoux, A., and Kirchner, J. W.: Evaluation of bedload transport predictions using flow resistance equations to account for macro-roughness in steep mountain streams, Water Resour. Res., 47, W08513, doi:10.1029/2011WR010645, 2011.

Nitsche, M., Rickenmann, D., Kirchner, J. W., Turowski, J. M., and Badoux, A.: Macroroughness and variations in reach-averaged flow resistance in steep mountain streams, Water Resour. Res., 48, W12518, doi:10.1029/2012WR012091, 2012.
Papanicolaou, A. N., Bdour, A., and Wicklein, E.: Onedimensional hydrodynamic/sediment transport model applicable to steep mountain streams, J. Hydraul. Res., 42, 357-375, doi:10.1080/00221686.2004.9641204, 2004.

Parker, G.: Transport of gravel and sediment mixtures, in: Sedimentation Engineering: Theories, Measurements, Modeling, and Practice, Vol. 110 of ASCE Manuals and Reports on Engineering Practice, American Society of Civil Engineers (ASCE), Chap. 3, 165-252, 2008.

Radice, A., Giorgetti, E., Brambilla, D., Longoni, L., and Papini, M.: On integrated sediment transport modelling for flash events in mountain environments, Acta Geophys., 60, 191-2013, doi:10.2478/s11600-011-0063-8, 2012.

Recking, A.: A comparison between flume and field bed load transport data and consequences for surface-based bed load transport prediction, Water Resour. Res., 46, W03518, doi:10.1029/2009WR008007, 2010.

Recking, A.: Simple method for calculating reach-averaged bed-load transport, J. Hydraul. Eng.-ASCE, 139, 70-75, doi:10.1061/(ASCE)HY.1943-7900.0000653, 2013a.

Recking, A.: An analysis of nonlinearity effects on bed load transport prediction, J. Geophys. Res.-Earth Surf., 118 , 1264-1281, doi:10.1002/jgrf.20090, 2013b.

Reid, L. M. and Dunne, T.: Sediment budgets as an organizing framework in fluvial geomorphology, in: Tools in Fluvial Geomorphology, edited by: Kondolf, G. M. and Piégay, H., John Wiley and Sons, Ltd., Chap. 16, 463-500, 2003.

Rickenmann, D.: Comparison of bed load transport in torrent and gravel bed streams, Water Resour. Res., 37, 3295-3305, doi:10.1029/2001WR000319, 2001.

Rickenmann, D.: Alluvial steep channels: flow resistance, bedload transport prediction, and transition to debris flows, in: Gravel Bed Rivers: Processes, Tools, Environment, edited by: Church, M., Biron, P. M., and Roy, A. G., John Wiley \& Sons, 386-397, Chichester, UK, 2012.

Rickenmann, D. and Recking, A.: Evaluation of flow resistance in gravel-bed rivers through a large field data set, Water Resour. Res., 47, W07538, doi:10.1029/2010WR009793, 2011.

Saltelli, A., Ratto, M., Tarantola, S., Campolongo, F., European Commission, and Joint Research Centre of Ispra (I): Sensitivity analysis practices: strategies for model-based inference, Reliab. Eng. Syst. Safe., 91, 1109-1125, doi:10.1016/j.ress.2005.11.014, 2006.

Schälchli, U. and Kirchhofer, A.: Sanierung Geschiebehaushalt. Strategische Planung. Ein Modul der Vollzugshilfe Renaturierung der Gewässer, Swiss Federal Office for the Environment FOEN, Berne, Switzerland, 2012.

Schattan, P., Zappa, M., Lischke, H., Bernhard, L., Thürig, E., and Diekkrüger, B.: An approach for transient consideration of forest change in hydrological impact studies, in: Climate and Land Surface Changes in Hydrology: Proceedings of H01, IAHS-IAPSOIASPEI Assembly, Vol. 359 of IAHS Publ., 311-319, 2013.

Sternberg, H.: Untersuchungen über Längen- und Querprofil geschiebeführender Flüsse, Zeitschrift für Bauwesen, 25, 483506, 1875.

Stricker, B.: Murgänge im Torrente Riascio (TI): Ereignisanalyse, Auslösefaktoren und Simulation von Ereignissen mit RAMMS, M.S. thesis, University of Zurich and Swiss Federal Research Institute WSL, 2010. 
Totschnig, R., Sedlacek, W., and Fuchs, S.: A quantitative vulnerability function for fluvial sediment transport, Nat. Hazards, 58, 681-703, doi:10.1007/s11069-010-9623-5, 2011.

Turowski, J. M.: Semi-alluvial channels and sediment-flux-driven bedrock erosion, in: Gravel-bed Rivers: Processes, Tools, Environments, edited by: Church, M., Biron, P. M., and Roy, A. G., John Wiley \& Sons, 401-418, Chichester, UK, 2012.

Turowski, J. M., Badoux, A., and Rickenmann, D.: Start and end of bedload transport in gravel-bed streams, Geophys. Res. Lett., 38, L04401, doi:10.1029/2010GL046558, 2011.

Unfer, G., Hauer, C., and Lautsch, E.: The influence of hydrology on the recruitment of brown trout in an Alpine river, the Ybbs River, Austria, Ecol. Freshw. Fish, 20, 438-448, doi:10.1111/j.16000633.2010.00456.x, 2011.

VAW Laboratory of Hydraulics, Hydrology and Glaciology, ETH Zurich: Geschiebehaushalt Kleine Emme, Studie über den Geschiebehaushalt der Kleinen Emme und Prognose der zukünftigen Sohlenveränderungen zwischen der Lammschlucht und der Mündung in die Reuss, Tech. rep. no. 4106, by order of Tiefbauamt des Kantons Luzern, Zurich, Switzerland, 1997 (unpublished report).
Viviroli, D., Zappa, M., Gurtz, J., and Weingartner, R.: An introduction to the hydrological modelling system PREVAH and its preand post-processing-tools, Environ. Modell. Softw., 24, 12091222, doi:10.1016/j.envsoft.2009.04.001, 2009.

Wicks, J. and Bathurst, J.: SHESED: a physically based, distributed erosion and sediment yield component for the SHE hydrological modelling system, J. Hydrol., 175, 213-238, doi:10.1016/S00221694(96)80012-6, 1996.

Wilcock, P. R. and Crowe, J. C.: Surface-based transport model for mixed-size sediment, J. Hydraul. Eng.-ASCE, 129, 120-128, doi:10.1061/(ASCE)0733-9429(2003)129:2(120), 2003.

Yager, E. M., Kirchner, J. W., and Dietrich, W. E.: Calculating bed load transport in steep boulder bed channels, Water Resour. Res., 43, W07418, doi:10.1029/2006WR005432, 2007. 